\title{
Sex Differences in the Cannabinoid Modulation of Appetite, Body Temperature and Neurotransmission at POMC Synapses
}

\author{
Shanna Diaz Borzoo Farhang Joshua Hoien Megan Stahlman Nadira Adatia \\ Jeremy M. Cox Edward J. Wagner \\ Department of Basic Medical Sciences, Western University of Health Sciences, Pomona, Calif., USA
}

\section{Key Words}

Cachexia $\cdot$ Obesity $\cdot$ GABA $\cdot$ Glutamate $\cdot$ CB1 receptor

\begin{abstract}
We sought to determine whether sex differences exist for the cannabinoid modulation of appetite, body temperature and neurotransmission at pro-opiomelanocortin (POMC) synapses. Gonadectomized male and female guinea pigs were outfitted to monitor core body temperature and injected with either the CB1 receptor agonist WIN 55,212-2 (1 mg/kg s.c.), antagonist AM251 (3 mg/kg s.c.) or vehicle ( $1 \mathrm{ml} / \mathrm{kg}$ s.c.) and evaluated for changes in six indices of feeding behavior under ad libitum conditions for 7 days. WIN 55,212-2 elicited an overt, sexually differentiated hyperphagia in which males displayed larger increases in hourly and daily intake, consumption/gram body weight, meal size and meal duration. The agonist also produced a more robust acute hypothermia in males than in females. In addition, males were more sensitive to the hypophagic effect of AM251, manifested by comparatively sizeable decreases in hourly intake, consumption/gram body weight, meal frequency and hyperthermia. To gain additional insight into the cellular mechanism underlying cannabinoid regulation of energy homeostasis, we performed whole-cell patch clamp recordings in hypothalamic slices prepared from go-
\end{abstract}

nadectomized male and female guinea pigs, and monitored miniature excitatory and inhibitory postsynaptic currents (mEPSCs and mIPSCs) in arcuate (ARC) neurons. ARC neurons from females exhibited a higher basal mEPSC frequency. WIN 55,212-2 dose-dependently reduced mEPSC and mIPSC frequency; however, cells from males were far less sensitive to the CB1 receptor-mediated decrease in mIPSC frequency. These effects were observed in neurons subsequently identified as POMC neurons. These data reveal pronounced sex differences in how cannabinoids influence the hypothalamic control of homeostasis.

Copyright $\odot 2009$ S. Karger AG, Basel

\section{Introduction}

There are a number of cannabinoid-regulated biological processes that are sexually differentiated. For example, female rats are more sensitive than their male counterparts to the antinociceptive effects of cannabinoids in response to noxious thermal and mechanical stimuli [1, 2]. Female rodents are also more sensitive to both the hyperlocomotor and cataleptic effects of cannabinoids [13]. In addition, women are more susceptible to the cannabinoid-induced hemodynamic changes observed with the transition between the supine and standing position 
[4], and are more vulnerable to the cannabinoid-induced impairment of visuospatial memory [5], than their male counterparts. On the other hand, male rats are more sensitive to the stimulatory effect of the centrally administered CB1 receptor agonist CP 55,940 on the consumption of sweetened condensed milk [6]; a dose 10X higher is required to elicit an equivalent intake in females. Moreover, men report greater subjective assessments of marijuana intoxication (i.e. more euphoric, high, stimulated), and nicotine pretreatment potentiates the marijuana-induced cardiovascular effects (e.g. increased heart rate) and the behavioral ratings to a greater extent in men than in women [7].

It has long been known that exogenous and endogenous cannabinoids stimulate appetite in both humans and animal models of feeding $[8,9]$. Indeed, $\Delta^{9}$-tetrahydrocannabinol (THC) has proven effective in ameliorating the cachexia associated with cancer and HIV/AIDS [10-12], as has rimonabant in mitigating against obesity and associated metabolic syndrome $[13,14]$. The effects of cannabinoids on food consumption are complex and involve interactions between the gut, liver, pancreas, adipose tissue and brainstem $[8,9,15]$. While these components are undoubtedly important to the overall process, cannabinoid actions within several nuclei comprising the hypothalamic feeding circuitry also appear instrumental to the regulation of energy homeostasis. For example, $\mathrm{CB} 1$ receptors are expressed in the lateral hypothalamic area (LHA), dorsomedial nucleus, ventromedial nucleus (VMN), arcuate nucleus (ARC) and the paraventricular nucleus (PVN) [9, 16]. In addition, the focal injection of THC into the LHA [17], as well as of THC and anandamide into the VMN [18], induces hyperphagia in rats. Moreover, endogenous cannabinoids retrogradely inhibit GABAergic neurotransmission at orexigenic melaninconcentrating hormone $(\mathrm{MCH})$ synapses in the LHA [19], which would account for the cannabinoid-induced depolarization and the accompanying increase in firing rate of these cells [20]. Furthermore, cannabinoids increase neuropeptide Y (NPY) release from the ARC [21], and decrease glutamatergic synaptic input onto anorexigenic pro-opiomelanocortin (POMC) neurons from transgenic mice [22] and guinea pigs [23,24]. Finally, the adipostat leptin decreases hypothalamic concentrations of 2-arachidonyl glycerol [25], and physiologically antagonizes glucocorticoid stimulation of endogenous cannabinoid biosynthesis and release in the PVN [26].

The extensive precedence for sex differences in cannabinoid regulated biology provided us with a compelling rationale to further investigate the sexually dispa-

Sex Differences, Cannabinoids and

Energy Homeostasis rate, cannabinoid-induced modulation of appetite and feeding behavior. The guinea pig is a valid, well-established animal model for appetite regulation. There has been an appreciable amount of information gathered over the past thirty years on the circadian rhythmicity [27], the effects of fasting [28, 29], and the operant cues [28] associated with guinea pig feeding behavior. Guinea pigs also have proven to be a more sensitive animal model than rats or mice for the study of the anorectic properties of serotonergics such as fenfluramine [30] and fluoxetine [31], and like humans suffer from the inability to manufacture their own vitamin $C[27,32]$. In addition, the female guinea pig has an ovulatory cycle that is 14-18 days in length with a true luteal phase, and is nearly identical to the primate female [33-36]. Moreover, the latency of the luteinizing hormone surge following a systemic $17 \beta$ estradiol injection in the ovariectomized guinea pig ani$\mathrm{mal}$ is the same in the non-human primate $[33,37]$. Thus, we examined the potential for disparate, microstructural changes in meal pattern caused by the CB1 receptor agonist WIN 55,212-2 or antagonist AM251 in gonadectomized male and female guinea pigs in order to ascertain how cannabinoids may differentially impact the appetitive and consummatory components, as well as the circadian rhythmicity, of feeding in males and females. We also monitored cannabinoid-induced alterations in core body temperature. To further elucidate the cellular mechanisms through which cannabinoids may modulate appetite in a sexually differentiated fashion, we performed whole-cell patch recordings to look at CB1 receptor agonist-induced presynaptic inhibition of miniature excitatory and inhibitory postsynaptic currents (mEPSCs and mIPSCs, respectively) in hypothalamic slices using biocytin-filled electrodes. For comparison, we evaluated food intake in gonadally intact male and female CB1 receptor knockout mice and their littermate controls. The results reveal that males are much more sensitive to the appetite-modulating properties of cannabinoids, which correlates with a marked sex difference in the cannabinoid-induced presynaptic inhibition of GABAergic synaptic input onto anorexigenic POMC neurons.

\section{Animals and Methods}

Animals and Treatments

All animal procedures described in this study are in accordance with institutional guidelines based on NIH standards. Male and female Topeka guinea pigs (250-390 g) were obtained from Elm Hill Breeding Labs (Chelmsford, Mass., USA), kept under controlled temperature $\left(69-73^{\circ} \mathrm{F}\right)$ and light (12 h on/12 h off), 
and provided with food and water ad libitum. They were anesthetized with ketamine/xylazine anesthesia (33 and $6 \mathrm{mg} / \mathrm{kg}$ s.c., respectively), gonadectomized and simultaneously implanted with a temperature datalogger (SubCue; Calgary, Alta., Canada) into the abdominal cavity to subsequently record temporal fluctuations and cannabinoid-induced changes in core body temperature. The animals were allowed to recover for 4-6 days prior to experimentation.

$\mathrm{CB} 1$ receptor knockout mice were derived from a C57BL/6J background, and kindly provided by Dr. Billy Martin, Virginia Commonwealth University. These transgenic animals were bred in-house, and the genetic karyotyping for each animal was accomplished starting with the isolation of genomic DNA from a small piece of ear lobe obtained via ear punch while the animal was under isoflurane (2\%) anesthesia. The following primers (Integrated DNA Technologies, Inc., San Diego, Calif., USA) were used: (1) a common forward primer (GTACCATCACCACAGACCTCCTC), (2) a CB1 receptor knockout primer (AAGAACGAGATCAGCAGCCTCTGTT), and (3) a wild-type primer (GGATTCAGAATCATGAAGCACTCCA). Amplicons $150 \mathrm{bp}$ (for the $\mathrm{CB} 1$ receptor knockout) and $300 \mathrm{bp}$ (for the wild type) in length were generated via PCR according to the following protocol: (1) a 5-min incubation at $95^{\circ} \mathrm{C}$, (2) 25 cycles each consisting of a 1 -minute incubation at $95^{\circ} \mathrm{C}$, a 1 -min incubation at $60^{\circ} \mathrm{C}$ and a 2 -min incubation at $72^{\circ} \mathrm{C}$, and (3) a 5 -min incubation at $72^{\circ} \mathrm{C}$.

\section{Drugs}

Unless otherwise specified, all drugs were purchased from Tocris Cookson, Inc. (Ellisville, Mo., USA). For the behavioral experiments, a mixture of cremephor/ethanol/0.9\% saline (1:1:18; $\mathrm{v} / \mathrm{v} / \mathrm{v}$ ) was used to solvate WIN 55,212-2 and AM251. For the electrophysiology experiments, tetrodotoxin (TTX) with citrate (Alomone Labs, Jerusalem, Israel) was dissolved in Ultrapure $\mathrm{H}_{2} \mathrm{O}$ to a stock concentration of $1 \mathrm{mM}$. cis-4-[Phosphomethyl]-2-piperidinecarboxylic acid (CGS 19755; $10 \mathrm{mM}$ ) was dissolved in $0.1 \mathrm{~N}$ $\mathrm{NaOH}$ and then diluted to the final volume with UltraPure $\mathrm{H}_{2} \mathrm{O}$. WIN 55,212-2 and NBQX were dissolved in dimethyl sulfoxide to stock concentrations of $10 \mathrm{mM}$. The stock solution of SR 95531 (10 $\mathrm{mM}$ ) was prepared with UltraPure $\mathrm{H}_{2} \mathrm{O}$.

\section{Feeding Behavior Paradigm}

The behavioral experiments were conducted using a four-cage Comprehensive Lab Animal Monitoring System (Columbus Instruments, Columbus, Ohio, USA) from which we monitored 5 parameters of feeding: hourly and daily intake, as well as meal frequency, size and duration. An electronic balance measured the amount of food contained within a food dish and separate spillage container that sat atop of it, with the difference being the actual amount of food consumed. Sensors detected the presence of the animal's head over the food dish, monitored the time spent over it and the amount of food consumed. This information was continuously transmitted to an A/D converter. Provided the animal had eaten a minimum of $10 \mathrm{mg}$ of food by the time it withdrew its head, the event was logged as a meal and the actual mass of food eaten and the time necessary to consume it were digitally stored in the experimental data file. Feeding behavior was assessed under conditions in which food and water were available ad libitum prior to and during the 7 days of testing. Daily food intake was taken as the total amount consumed at the end of a 24-hour monitoring session. Meal frequency equaled the number of meals con- sumed per unit time. Meal size was defined as the amount of food eaten in a given hour divided by the number of meals in that same hour. Meal duration referred to the amount of time necessary to eat a meal. The animals were allowed to acclimate in the feeding chambers for $24 \mathrm{~h}$ per day over a 3 -day period. Each morning they were weighed, handled, and returned to their respective chambers. After the 3-day acclimation session, we initiated the 7-day monitoring phase during which the animals were weighed, injected each morning with either WIN 55,212-2 (1 mg/kg s.c.), AM251 (3 mg/kg s.c.) or their cremephor/ethanol $/ 0.9 \%$ saline vehicle ( $1 \mathrm{ml} / \mathrm{kg}$ s.c.), immediately placed in their feeding chambers and then subjected to continuous monitoring of each of the 5 above-described feeding parameters over the 24-hour time span.

\section{In vitro Hypothalamic Slice Preparation}

On the day of experimentation, the animal was decapitated, its brain removed from the skull and the hypothalamus dissected. We then mounted the resultant hypothalamic block on a cutting platform that was then secured in a vibratome well filled with icecold, oxygenated $\left(95 \% \mathrm{O}_{2}, 5 \% \mathrm{CO}_{2}\right)$ artificial cerebrospinal fluid (aCSF, in mM: $\mathrm{NaCl}, 124 ; \mathrm{NaHCO}_{3}$ 26; dextrose, 10; HEPES, 10; $\left.\mathrm{KCl}, 5 ; \mathrm{NaH}_{2} \mathrm{PO}_{4}, 2.6 ; \mathrm{MgSO}_{4}, 2 ; \mathrm{CaCl}_{2}, 1\right)$. Five coronal slices $(350$ $\mu \mathrm{M})$ through the ARC were then cut. The slices were transferred to an auxiliary chamber containing oxygenated aCSF, and kept there until electrophysiological recording.

\section{Electrophysiology}

Whole-cell patch recordings in hypothalamic slices were performed as previously described $[23,24]$. Briefly, during the recording session, slices were maintained in a chamber perfused with a warmed $\left(35^{\circ} \mathrm{C}\right)$, oxygenated aCSF that was identical to that described above, the exception being an increase in the $\mathrm{CaCl}_{2}$ concentration to $2 \mathrm{mM}$. Artificial CSF and all drugs (diluted with aCSF) were perfused via a peristaltic pump at a rate of $1.5 \mathrm{ml} / \mathrm{min}$. Patch electrodes were assembled from borosilicate glass (World Precision Instruments, Sarasota, Fla., USA; $1.5 \mathrm{~mm}$ OD) pulled on a P-97 Flaming Brown puller (Sutter Instrument Co., Novato, Calif., USA), and filled with the following (in $\mathrm{mM}$ ): potassium gluconate, 128; $\mathrm{NaCl}, 10 ; \mathrm{MgCl}_{2}$, 1; EGTA, 11; HEPES, 10; ATP, 1.2; GTP, $0.4 ; 0.35-0.4 \%$ biocytin; adjusted to a $\mathrm{pH}$ of $7.3-7.4$ with $1.0 \mathrm{~N} \mathrm{KOH} ; 297-321$ mosm. Electrode resistances varied from 3 to $8 \mathrm{M} \Omega$. A Multiclamp 700A preamplifier (Axon Instruments, Foster City, Calif., USA) amplified potentials and passed current through the electrode. The patch electrode was advanced into the ARC with a positive pressure applied to the back of the electrode using a 5 -ml syringe connected by polyethylene tubing to the electrode holder. Once the electrode came up against a cell membrane, as indicated by a small decrease in the monitored current deflection (20-50\% of the initial amplitude), a slight negative pressure was applied via suction to form a stable gigaohm seal. We obtained whole cell recordings by applying additional suction to rupture the membrane under the electrode. Membrane currents were recorded in voltage clamp with access resistances ranging from 8 to $20 \mathrm{M} \Omega(\mathrm{n}=70)$, and underwent analog-digital conversion via a Digidata $1322 \mathrm{~A}$ interface coupled to pClamp 8.2 software (Axon Instruments). The access resistance, as well as the resting membrane potential (RMP) and the input resistance $\left(\mathrm{R}_{\text {in }}\right)$, were monitored throughout the course of the recording. If the access resistance deviated more than $10 \%$ from its original value, 
the recording was ended. Low-pass filtering of the currents was conducted at a frequency of $2 \mathrm{kHz}$. The liquid junction potential was calculated to be $-10 \mathrm{mV}$, and was corrected for during data analysis using pClamp software.

Synaptic transmission in the ARC was evaluated as described previously $[23,24]$. We recorded mEPSCs and mIPSCs in the presence of TTX $(500 \mathrm{nM})$ and the appropriate receptor antagonists from holding potentials of -75 and $-30 \mathrm{mV}$, respectively. After collecting a 3- to 4-min segment of baseline data, we perfused WIN 55,212-2 (30 $\mathrm{nM}$ to $10 \mu \mathrm{M})$ for $4 \mathrm{~min}$, and then recorded mEPSCs or mIPSCs in the presence of agonist. The threshold for mEPSC or mIPSC detection was set at least $3 \mathrm{pA}$ below or above the baseline holding current as assessed from the headstage output, and continuously monitored throughout each 3 - to 4-min recording period. Information on interval and amplitude was obtained from at least 100 contiguous mEPSCs and mIPSCs, which we used to evaluate cannabinoid-induced alterations in frequency and amplitude as assessed from cumulative probability plots. We also monitored mEPSC and mIPSC decay to account for possible cannabinoid-induced changes in kinetics.

To pharmacologically characterize the effects of CB1 receptor activation on mEPSC and mIPSC frequency and amplitude, ARC neurons from gonadectomized male and female animals were tested with various concentrations of WIN 55,212-2 (0.03-10 $\mu \mathrm{M})$. Composite dose-response curves were generated from the following modification of the Hill equation:

$$
\begin{aligned}
& \Delta \mathrm{f}=100-\left(\Delta \mathrm { f } _ { \operatorname { m a x } } \cdot \left([\mathrm{WIN} 55,212-2]^{\mathrm{n}} /\left([\mathrm{WIN} 55,212-2]^{\mathrm{n}}\right.\right.\right. \\
& \left.\left.\left.+\left(\mathrm{IC}_{50}\right)^{\mathrm{n}}\right)\right)\right),
\end{aligned}
$$

where $\Delta f_{\max }$ is the maximal inhibition of mEPSC or mIPSC frequency or amplitude, $\mathrm{IC}_{50}$ represents the agonist potency to inhibit these parameters, and $\mathrm{n}$ is the Hill slope. Currents measured in the presence of varying concentrations of WIN 55,212-2 were normalized with respect to their baseline frequency and amplitude.

\section{Immunohistofluorescence}

After recording, some slices were processed for phenotypic identification as previously described [38]. Briefly, slices were fixed with 4\% paraformaldehyde (PFM) in Sorensen's phosphate buffer ( $\mathrm{pH}$ 7.4) for 90-180 min. They were then immersed overnight in 20\% sucrose dissolved in Sorensen's buffer and frozen in Tissue-Tek embedding medium (Miles, Inc., Elkhart, Ind., USA) the next day. Coronal sections $(20 \mu \mathrm{m})$ were cut on a cryostat and mounted on charged slides. These sections were washed with $0.1 \mathrm{M}$ sodium phosphate buffer ( $\mathrm{pH} 7.4$ ) and then processed with streptavidin-AF488 (Invitrogen Corp., Carlsbad, Calif., USA) at a 1:300 dilution. After localizing the biocytin-filled neuron, the slides containing the appropriate sections were reacted with antibodies directed against either $\alpha$-melanocyte-stimulating hormone ( $\alpha$-MSH; Immunostar, Inc., Hudson, Wisc., USA) or cocaine-amphetamine-regulated transcript (CART; Phoenix Pharmaceuticals, Inc., Burlingame, Calif., USA) at 1:200 and 1:2,000 dilutions, respectively, using fluorescence immunohistochemistry [38].

\section{Statistics}

Comparisons between two groups were assessed via the Student's $t$ test. Comparisons between two or more groups were performed using multifactorial, repeated measures analysis of vari- ance (ANOVA) followed by the least significant difference (LSD) test. Differences were considered statistically significant if the probability of error was less than $5 \%$.

\section{Results}

Microstructural Analysis Reveals Sex Differences in the Cannabinoid Modulation of Feeding

We have shown previously that CB1 receptor activation and blockade, respectively, elicits hyperphagia and hypophagia associated with weight loss in gonadally intact fasted male guinea pigs [24]. To explore the potential for sex differences in the CB1 receptor-mediated modulation of appetite, we examined the effects of the CB1 receptor agonist WIN 55,212-2 (1 mg/kg s.c.) and antagonist AM251 (3 mg/kg s.c.) on the microstructure of meal pattern in gonadectomized male and female guinea pigs under ad libitum conditions for 7 days. Figure 1a depicts the hourly intake observed over a 24-hour period. Multifactorial ANOVA revealed significant main effects for both drug $\left(\mathrm{F}_{(1,1)}=135.37, \mathrm{p}<0.0001\right)$ and $\operatorname{sex}\left(\mathrm{F}_{(1,1)}=\right.$ 49.19, $\mathrm{p}<0.0001)$, indicating that systemic administration of WIN 55,212-2 and AM251, respectively, increased and decreased food consumption relative to the vehicletreated control group, and that males ate more than females. No signs of tolerance were observed over the course of the monitoring period. As shown in the interaction plot of figure $1 \mathrm{~b}$, there also was a significant interaction $\left(\mathrm{F}_{(1,1)}=30.51 ; \mathrm{p}<0.0001\right)$, meaning that the agonistinduced increase in hourly food intake, and the antagonist-induced decrease, were more substantial in males than in females. Examination of the temporal profile in figure 1a revealed an apparent biphasic effect of WIN $55,212-2$. In females, the agonist caused an acute increase in hourly intake that peaked $2 \mathrm{~h}$ after administration. This effect was transient in that hourly intake returned to normal within an hour after the peak increase, followed by an apparent compensatory hypophagia that lasted for $2 \mathrm{~h}$. Interestingly, there was a secondary hyperphagia that peaked $1 \mathrm{~h}$ into the dark phase (lights off at 19:00 h) and was maintained throughout the nocturnal period. By contrast, WIN 55,212-2 evoked an acute hyperphagic response in males of comparable magnitude to that observed in females, but this effect was much more prolonged and lasted up to $8 \mathrm{~h}$ after the peak hyperphagic response with no compensatory hypophagia. Moreover, the secondary, latent nocturnal hyperphagia was considerably more pronounced in males than in females. The effect of AM251 was also biphasic. AM251 clearly de- 


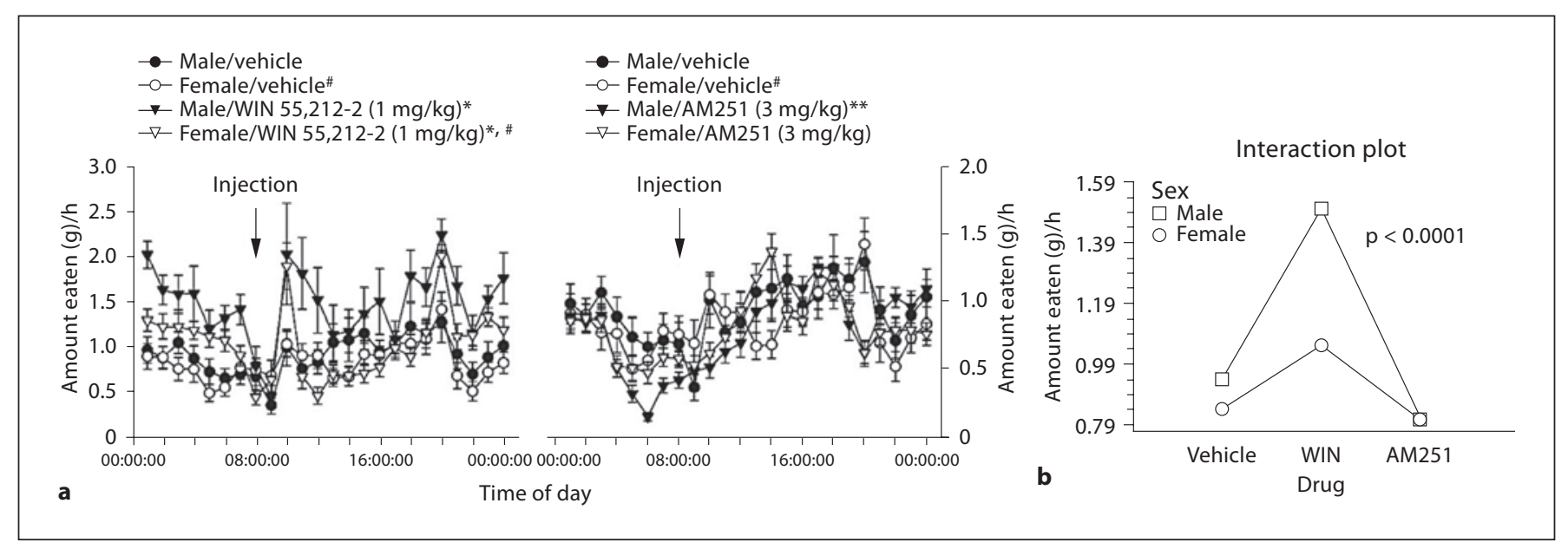

Fig. 1. Sex differences in cannabinoid-induced alterations in hourly food intake. a Gonadectomized male and female animals were injected with WIN 55,212-2 (1 mg/kg s.c.), AM251 (3 mg/kg s.c.) or their cremephor/ethanol/saline vehicle at 08:00 h and immediately placed back into their respective feeding chambers. The symbols represent means and vertical lines 2 SEM $(n=4)$ of the total amount of food consumed every hour over a 24-hour period. The data to the left of the injection arrow represent the average cumulative intake measured at hourly intervals from 1:00 to 8:00 a.m. across the 7 days of exposure. ${ }^{*}$ Values from animals treated with WIN 55,212-2 that are significantly different (multi-factorial ANOVA/LSD; $\mathrm{p}<0.05$ ) than those observed in vehicle-treated controls. "Values from females that are significantly different (multi-factorial ANOVA/LSD; $\mathrm{p}<0.05$ ) than those from their male counterparts. ${ }^{* *}$ Values from animals treated with AM251 that are significantly different (multi-factorial ANOVA/LSD; $\mathrm{p}<$ $0.05)$ than those observed in vehicle- or agonist-treated animals. b An interaction plot that illustrates the significant interaction between sex and drug, and the significant changes in hourly intake in agonist- and antagonist-treated animals. creased hourly intake in both male and female animals $2 \mathrm{~h}$ after administration, and then again during the nocturnal peak that occurred $1 \mathrm{~h}$ into the dark period. However, in males, the antagonist continued to suppress hourly intake throughout the latter half of the nocturnal period. Cannabinoid-induced changes in hourly intake were paralleled by sexually disparate alterations in the absolute food intake observed over a 24-hour period (drug: $\mathrm{F}_{(1,1)}=30.97, \mathrm{p}<0.0001 ;$ sex: $\mathrm{F}_{(1,1)}=10.36, \mathrm{p}<$ 0.002; interaction: $\mathrm{F}_{(1,1)}=7.44 ; \mathrm{p}<0.001$; fig. 2). WIN $55,212-2$ increased daily intake, and this agonist-induced elevation was substantially greater in males than in females. In looking strictly at the 24-hour intake, AM251 caused a modest yet statistically insignificant decrease that also appeared greater in males than in females. To account for variations in body weight between batches of animals, or over the course of the experimental paradigm, we also examined cannabinoid effects on the amount of food consumed per gram body weight. Multifactorial ANOVA uncovered a significant main effect of drug $\left(\mathrm{F}_{(1,1)}=17.97, \mathrm{p}<0.0001\right)$ but not $\operatorname{sex}\left(\mathrm{F}_{(1,1)}=1.44, \mathrm{p}<\right.$ $0.24)$, as well as a significant interaction $\left(\mathrm{F}_{(1,1)}=11.42\right.$, $\mathrm{p}<0.0001$ ). Thus, as shown in figure 3, WIN 55,212-2 increased the amount of food eaten per gram body weight to a greater extent in males than in females, whereas AM251 decreased the amount of food eaten per gram body weight in males, but not females.

Cannabinoids and sex exhibited significant main effects on meal frequency, as well as a significant interaction (drug: $\mathrm{F}_{(1,1)}=108.44, \mathrm{p}<0.0001$; sex: $\mathrm{F}_{(1,1)}=18.71$, $\mathrm{p}<0.0001$; interaction: $\mathrm{F}_{(1,1)}=38.37, \mathrm{p}<0.0001$; fig. 4). However, in this case, females exhibited both a lower intrinsic meal frequency and were more responsive than males to the stimulatory effect of WIN 55,212-2 (fig. 4b). As shown in figure $4 \mathrm{a}$, the agonist-induced increase in meal frequency seen in females was biphasic in that there was an initial increase that peaked $2 \mathrm{~h}$ after drug administration, and a delayed increase that began in the late afternoon and continued on through the dark phase of the light cycle. In males, only the delayed increase was observed. On the other hand, AM251 decreased meal frequency overall, but as illustrated by the interaction plot in figure $4 \mathrm{~b}$, this effect was conferred exclusively to males. In fact, AM251 modestly elevated meal frequency in females. As shown in the temporal profile in figure $4 \mathrm{a}$, the antagonist-induced decrease in male meal fre- 


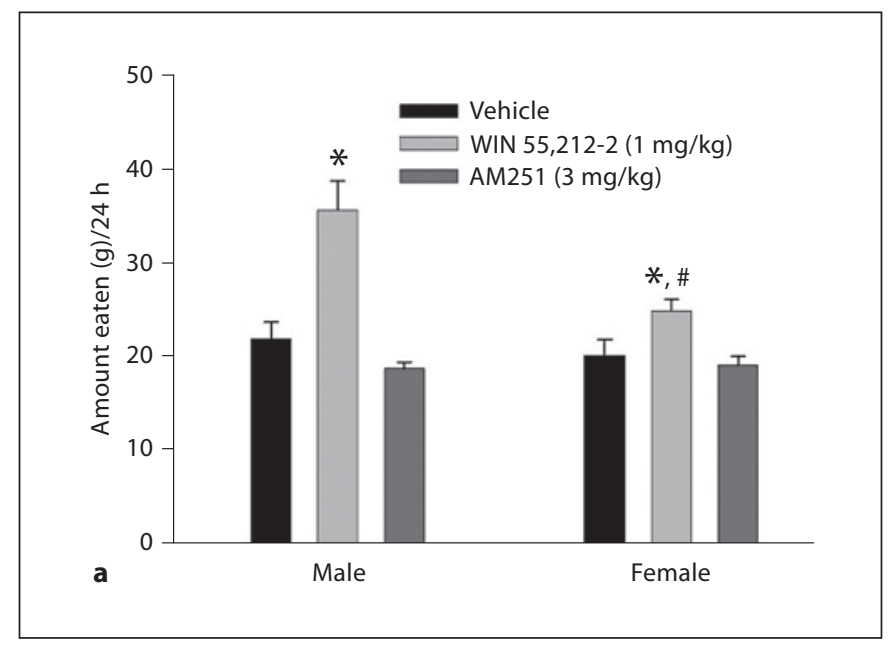

Fig. 2. Sex differences in cannabinoid-induced alterations in daily food intake. a Gonadectomized male and female animals were injected with WIN 55,212-2 (1 mg/kg s.c.), AM251 (3 mg/kg s.c.) or their cremephor/ethanol/saline vehicle at 08:00 $\mathrm{h}$ and immediately placed back into their respective feeding chambers. The vertical bars represent means and vertical lines 1 SEM $(n=4)$ of the total amount of food consumed over a 24 -hour period. * Values

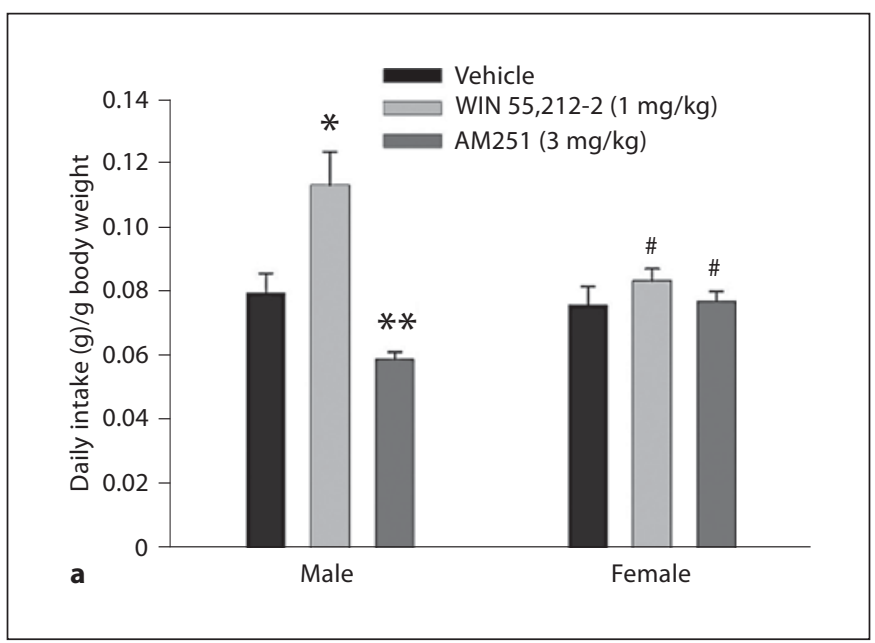

Fig. 3. Sex differences in cannabinoid-induced changes in food intake per gram body weight. a Gonadectomized male and female animals were injected with WIN 55,212-2 (1 mg/kg s.c.), AM251 (3 mg/kg s.c.) or their cremephor/ethanol/saline vehicle at 08:00 h and immediately placed back into their respective feeding chambers. The vertical bars represent means and vertical lines 1 SEM $(\mathrm{n}=4)$ of the total amount of food consumed over a 24-hour period divided by the animal's body weight determined that same day. ${ }^{*}$ Values from animals treated with WIN 55,212-2 that are significantly different (multifactorial ANOVA/LSD; $\mathrm{p}<0.05$ )

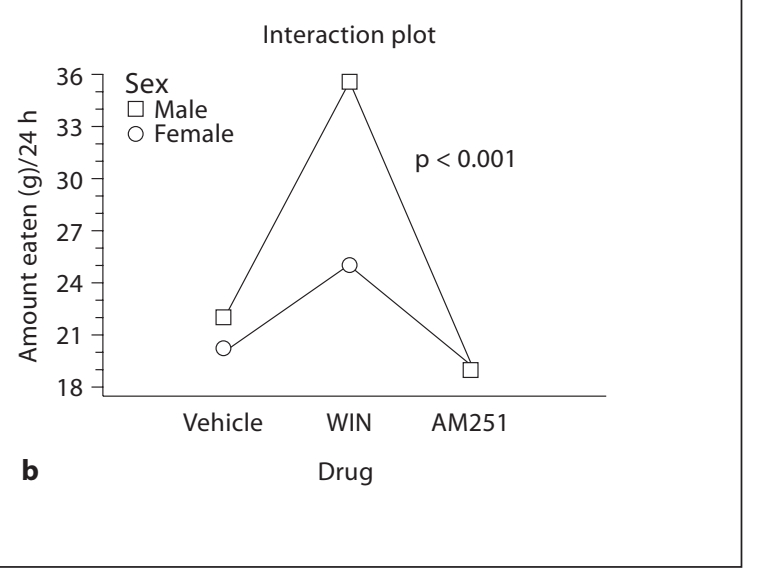

from animals treated with WIN 55,212-2 that are significantly different (multi-factorial ANOVA/LSD; $\mathrm{p}<0.05$ ) than those observed in vehicle-treated controls. "Values from female animals that are significantly different (multi-factorial ANOVA/LSD; $\mathrm{p}<$ 0.05 ) than those from males. $\mathbf{b}$ An interaction plot illustrating the significant interaction between sex and drug, and the significant increase in daily food intake in agonist-treated animals.

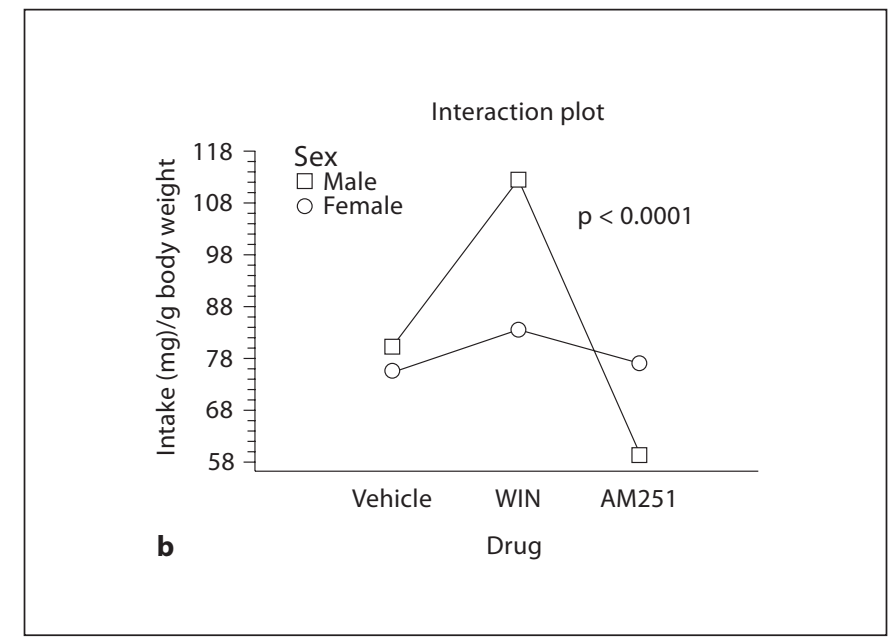

than those observed in vehicle-treated controls. "Values from females that are significantly different (multifactorial ANOVA/ LSD; $\mathrm{p}<0.05)$ than those from males. ${ }^{*}$ Values from animals treated with AM251 that are significantly different (multi-factorial ANOVA/LSD; $\mathrm{p}<0.05$ ) than those observed in vehicle- or agonist-treated animals. b An interaction plot that illustrates the significant interaction between sex and drug, and the significant changes in the amount of food consumed per gram body weight in agonist- and antagonist-treated animals. 


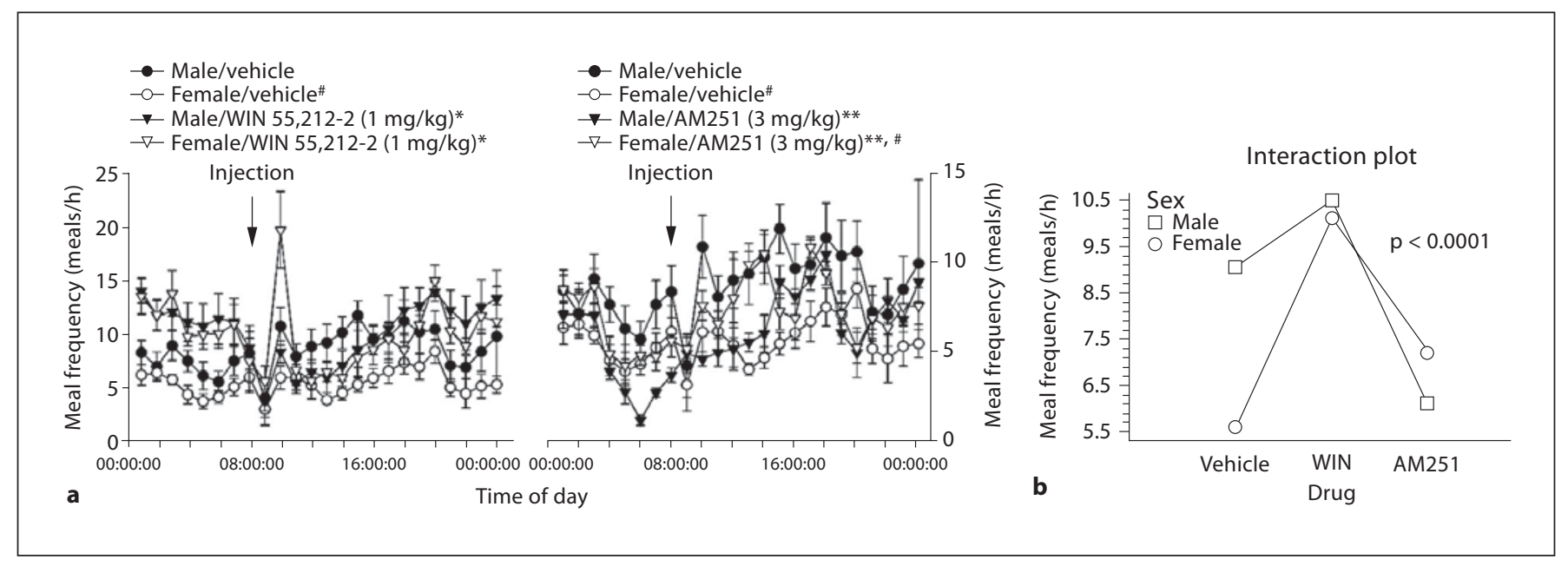

Fig. 4. Sex differences in the cannabinoid modulation of meal frequency. a Gonadectomized male and female animals were injected with WIN 55,212-2 (1 mg/kg s.c.), AM251 (3 mg/kg s.c.) or their cremephor/ethanol/saline vehicle at 08:00 h and immediately placed back into their respective feeding chambers. The symbols represent means and vertical lines 2 SEM $(n=4)$ of the meal frequency defined as the number of meals eaten per hour over a 24 -hour period. * Values from animals treated with WIN $55,212-2$ that are significantly different (multi-factorial ANOVA/
LSD; $p<0.05)$ than those observed in vehicle-treated controls. \# Values from females that are significantly different (multi-factorial ANOVA/LSD; $\mathrm{p}<0.05$ ) than those from their male counterparts. ${ }^{* *}$ Values from animals treated with AM251 that are significantly different (multi-factorial ANOVA/LSD; $<<0.05$ ) than those observed in vehicle- or agonist-treated animals. b An interaction plot that illustrates the significant interaction between sex and drug, and the significant changes in meal frequency in agonist- and antagonist-treated animals. quency became apparent $2 \mathrm{~h}$ after administration and persisted for an additional $6 \mathrm{~h}$ into the late afternoon. There also was a robust reduction in meal frequency observed $1 \mathrm{~h}$ into the dark phase as well as a latent decrease evident throughout the latter half of the nocturnal period (fig. 4a). The appetite modulating properties of these cannabinoid ligands also were associated with alterations in meal size (drug: $\mathrm{F}_{(1,1)}=4.63, \mathrm{p}<0.01$; sex: $\mathrm{F}_{(1,1)}=0.08, \mathrm{p}>0.05$; interaction: $\mathrm{F}_{(1,1)}=21.19, \mathrm{p}<0.0001$; fig. 5) and sex-specific changes in meal duration (drug: $\mathrm{F}_{(1,1)}=31.59, \mathrm{p}<0.0001$; sex: $\mathrm{F}_{(1,1)}=20.85, \mathrm{p}<0.0001$; interaction: $\mathrm{F}_{(1,1)}=48.11, \mathrm{p}<0.0001$; fig. 6$)$. Thus, the significant stimulatory effects of WIN 55,212-2 on meal size and duration were due exclusively to its effects in males. In females, which exhibited higher intrinsic meal size and duration, the agonist actually decreased meal size overall and was without effect on meal duration (fig. 5b, 6b). The increases in the amount of food eaten per meal and meal duration observed in males became apparent within one hour, peaked within $2-3 \mathrm{~h}$, and lasted up to 7-9 h following the administration of the agonist (fig. 5a, 6a). AM251 also produced comparatively modest increases in meal size and duration in males, but had no effect in females.

\section{The Cannabinoid Modulation of Weight Gain and}

Body Temperature Is Sexually Differentiated

We found that the cannabinoid-induced alterations in feeding behavior correlated with changes in weight gained over the course of the 7-day monitoring period (drug: $\mathrm{F}_{(1,1)}=3.81, \mathrm{p}<0.05$; fig. 7). WIN 55,212-2 produced a slight increase in weight gain relative to vehicle-treated controls (14.6\% in males; $0.3 \%$ in females) that was not statistically significant. On the other hand, AM251 caused a robust reduction in weight gain $(16.8 \%$ vs. vehicle-treated control in males; $52.7 \%$ vs. vehicle-treated control in females). In keeping with their ability to activate and antagonize CB1 receptors, respectively, WIN 55,212-2 and AM251 also elicited considerable changes in core body temperature. The main drug effects were also associated with a significant effect of sex as well as a significant interaction (drug: $\mathrm{F}_{(1,1)}=1568.37, \mathrm{p}<0.0001$; sex: $\mathrm{F}_{(1,1)}=54.93, \mathrm{p}<0.0001$; interaction: $\mathrm{F}_{(1,1)}=114.30, \mathrm{p}<$ 0.0001 ; fig. 8). Acutely, WIN 55,212-2 elicited a marked hypothermia that peaked $\sim 3.5 \mathrm{~h}$ after administration and was $\sim 0.5^{\circ} \mathrm{C}$ more prominent in males than in females (fig. 8a). However, females showed an intrinsically higher core body temperature that was particularly evident during the nocturnal period (fig. 8a), and thus over- 


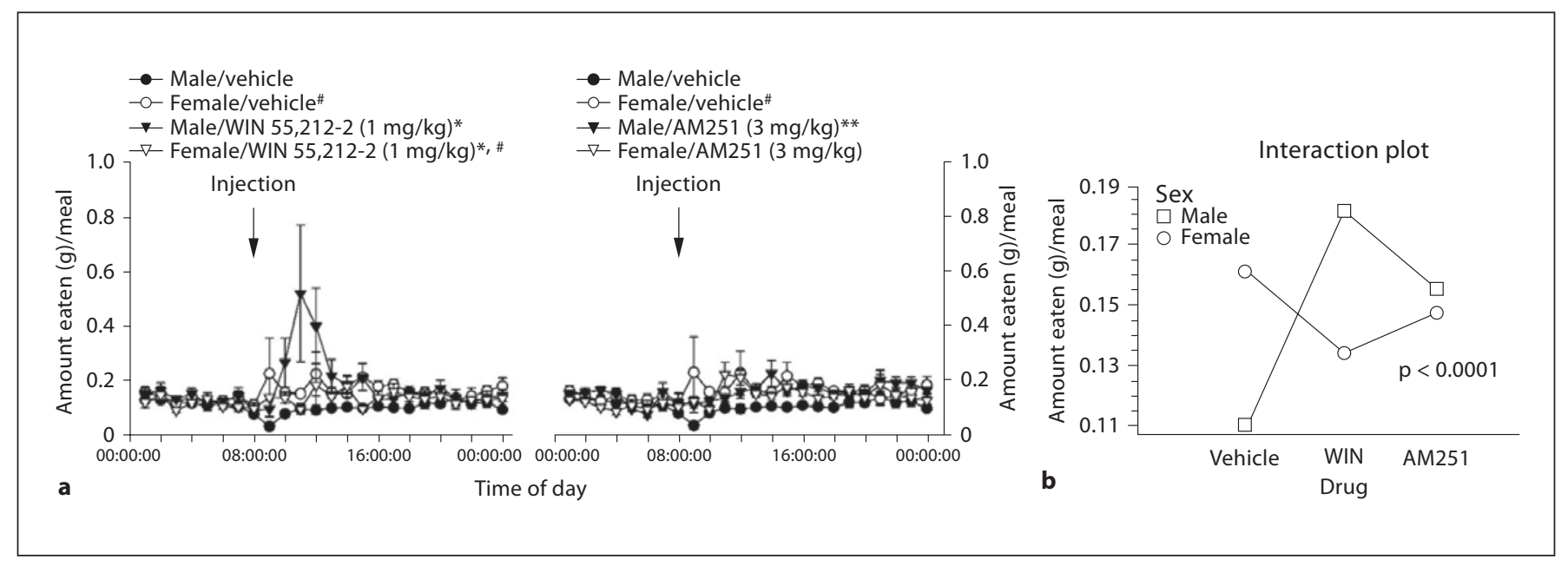

Fig. 5. Sex differences in the cannabinoid regulation of meal size. a Gonadectomized male and female animals were injected with WIN 55,212-2 (1 mg/kg s.c.), AM251 (3 mg/kg s.c.) or their cremephor/ethanol/saline vehicle at 08:00 h and immediately placed back into their respective feeding chambers. Symbols signify means and lines 2 SEM $(n=4)$ of the amount of food consumed in a given hour divided by the number of meals in that same hour. * Values from animals treated with WIN 55212-2 that are significantly different (multifactorial ANOVA/LSD; $\mathrm{p}<0.05$ ) than those from vehicle-treated controls. " Values from females that are significantly different (multi-factorial ANOVA/LSD; $<<0.05$ ) than those from males. ${ }^{*}$ Values from animals treated with AM251 that are significantly different (multi-factorial ANOVA/ LSD; $p<0.05$ ) than those observed in vehicle- or agonist-treated animals. b An interaction plot that illustrates the significant interaction between sex and drug, and the significant changes in meal size in agonist- and antagonist-treated animals.

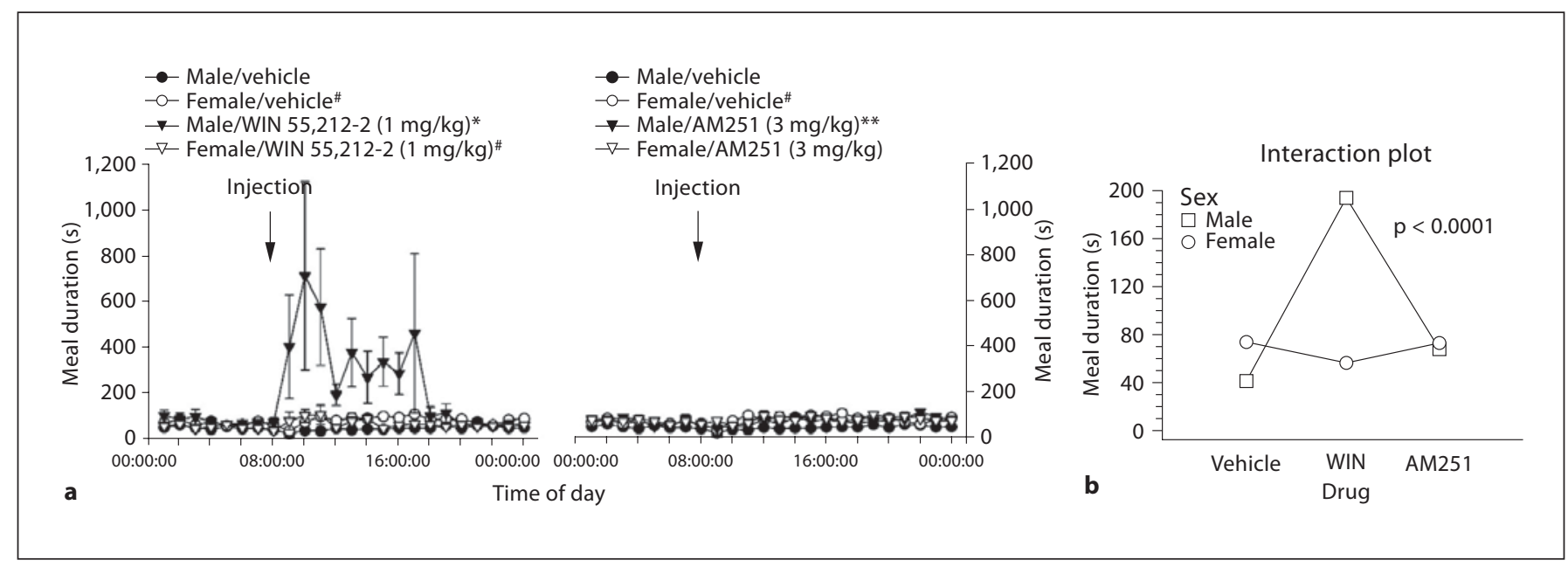

Fig. 6. Sex differences in cannabinoid-induced changes in meal duration. a Gonadectomized male and female animals were injected with WIN 55,212-2 (1 mg/kg s.c.), AM251 (3 mg/kg s.c.) or their cremephor/ethanol/saline vehicle at 08:00 h and immediately placed back into their respective feeding chambers. The symbols represent means and vertical lines 2 SEM $(n=4)$ of the meal duration defined as the time necessary to ingest an amount of food $\geq 10 \mathrm{mg}$. * Values from animals treated with WIN 55,2122 that are significantly different (multifactorial ANOVA/LSD; $\mathrm{p}<0.05)$ than those observed in vehicle-treated controls. "Values from females that are significantly different (multifactorial ANOVA/LSD; $\mathrm{p}<0.05)$ than those from their male counterparts. ** Values from animals treated with AM251 that are significantly different (multifactorial ANOVA/LSD; $\mathrm{p}<0.05$ ) than those observed in vehicle- or agonist-treated animals. b An interaction plot that illustrates the significant interaction between sex and drug, and the significant changes in meal duration in agonist- and antagonist-treated animals. 
all the hypothermic effect of the agonist was greater in females than in males (fig. 8b). By contrast, AM251 caused an increase in core body temperature that was overall more extensive in males and most striking during the dark phase.

\section{Sex Differences in the Cannabinoid-Induced}

Presynaptic Inhibition of GABAergic but Not

Glutamatergic Neurotransmission at POMC Synapses

We have demonstrated previously that $\mathrm{CB} 1$ receptor agonists presynaptically modulate ionotropic glutamatergic and GABAergic currents in POMC neurons as evidenced by: (1) a reduced amplitude of evoked EPSCs and IPSCs, (2) an increase in the S2:S1 ratio using the paired pulse paradigm, and (3) a decrease in the frequency, but not amplitude, of mEPSCs and mIPSCs [23, 24]. Given the sex differences in the cannabinoid-induced modulation of feeding behavior that were particularly pronounced for the agonist more so than the antagonist, we wanted to determine if this sexual disparity could be attributed in part to alterations in synaptic input onto anorexigenic POMC neurons. Sixty-seven neurons from the ARC of gonadectomized male and female guinea pigs were used to address this issue. No differences in RMP (males: $-52.3 \pm 1.9 \mathrm{mV}$; females: $-50.0 \pm 1.2 \mathrm{mV}$ ) or $\mathrm{R}_{\text {in }}$ (males: $605.7 \pm 58.3 \mathrm{M} \Omega$; females: $680.0 \pm 60.6 \mathrm{M} \Omega$ ) were observed. In addition, neither sex nor cannabinoid agonist treatment had any effect on the time-to-peak or the rate of inactivation of the mEPSCs or mIPSCs. Figure 9 shows current traces and cumulative probability plots derived from mEPSCs recorded in ARC neurons from male and female animals under baseline conditions and in the presence of WIN 55,212-2. Both doses of the agonist increased the interval between contiguous mEPSCs in cells from both males and females that translates into a graded decrease in mEPSC frequency of similar proportion between the sexes. These current traces and probability plots also show that the amplitudes of the mEPSCs recorded in the absence and presence of the agonist were of comparable magnitude. Similarly, WIN 55,212-2 decreased the frequency but not amplitude of mIPSCs recorded in ARC neurons. However, examination of the current traces shown in figure 10 indicated an apparently greater inhibitory effect of WIN 55,212-2 in the cell from the female animal. Whereas the intermediate dose of WIN 55,212-2 (100 nM) produced a clear, near maximal decrease in mIPSC frequency in the ARC neuron from the female animal, it was without effect on mIPSC frequency in the cell from the male animal. Only in the presence of the $1 \mu \mathrm{M}$ concentration of agonist was

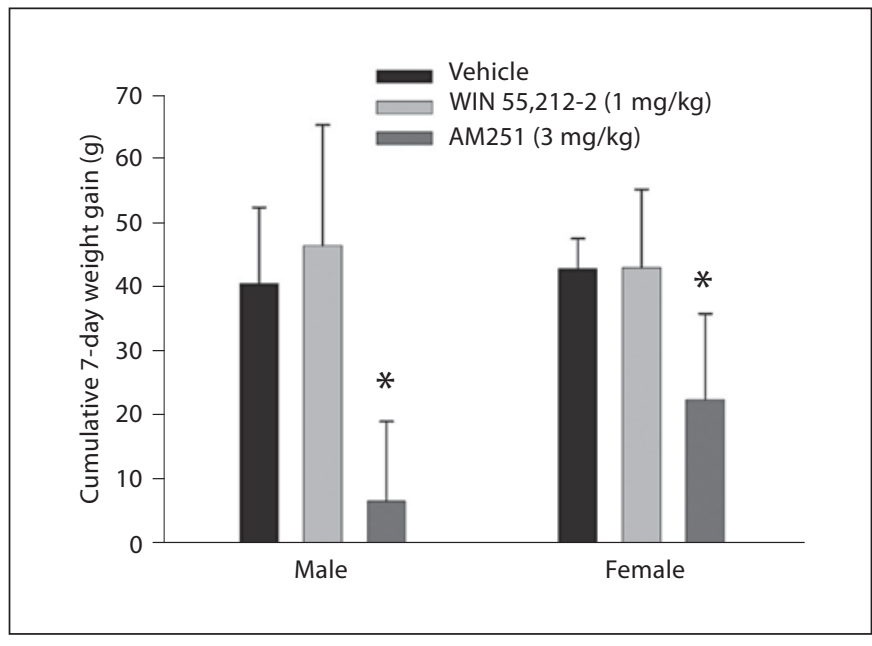

Fig. 7. Effects of CB1 receptor activation and blockade on weight gain. The vertical bars represent means and vertical lines 1 SEM of the weight accrued over the course of the 7-day monitoring period. * Values from AM251-treated animals that are significantly different (multifactorial ANOVA/LSD; $\mathrm{p}<0.05$ ) than those from vehicle-treated animals.

any appreciable decrease in MIPSC frequency observed. Indeed, this was substantiated upon systematic evaluation of the dose-response effects of the agonist on mEP$\mathrm{SC}$ and $\mathrm{mIPSC}$ frequency. Figure 11 shows the composite baseline characteristics for MEPSC and MIPSC frequency and amplitude in ARC neurons from male and female animals as well as the composite dose-inhibition relationships generated for the agonist-induced decrease in mEPSC and mIPSC frequency. It is noteworthy that under basal conditions, the mEPSC frequency in females is $\sim 2 \times$ higher than in males, whereas the mEPSC amplitudes, as well as the MIPSC frequencies and amplitudes, are of comparable magnitude. WIN 55,212-2 elicited dose-dependent decreases in mEPSC frequency, with an estimated $\mathrm{IC}_{50}$ of $50.4 \mathrm{nM}$ and $\Delta \mathrm{f}_{\max }$ of $55.7 \%$ in males that closely approximated those observed in females (69.1 nM and 49.8\%, respectively). WIN 55,212-2 also reduced mIPSC frequency in a dose-dependent fashion; however, in this instance and as was inferred from figure 10, ARC neurons from female animals were more sensitive to the inhibitory effect of the cannabinoid as manifest by a rightward shift in the dose-inhibition curve for the males and an $\sim 6 \times$ decrease in agonist potency (females: $\mathrm{IC}_{50}=72.6 \mathrm{nM}, \Delta \mathrm{f}_{\max }=50.6 \%$; males: $\mathrm{IC}_{50}=427.6 \mathrm{nM}$, $\left.\Delta \mathrm{f}_{\max }=47.2 \%\right)$. These presynaptic actions of WIN 55,2122 occurred in ARC neurons from male and female animals that were subsequently labeled via immunohisto- 
Fig. 8. Sex differences in the cannabinoidinduced change in core body temperature. Gonadectomized male and female animals were injected WIN 55,212-2 (1 mg/ $\mathrm{kg}$ s.c.), AM251 (3 mg/kg s.c.) or their cremephor/ethanol/saline vehicle at 08:00 h and immediately placed back into their respective feeding chambers. The symbols represent means and vertical lines 2 SEM $(\mathrm{n}=4)$ of the core body temperature recorded every seven minutes by data loggers inserted into the abdominal cavity at the time of castration. ${ }^{*}$ Values from animals treated with WIN 55,212-2 that are significantly different (multifactorial ANOVA/LSD; p < 0.05) than those observed in vehicle-treated controls. ${ }^{\text {Values }}$ from females that are significantly different (multifactorial ANOVA/LSD; $\mathrm{p}<0.05$ ) than those from males. ${ }^{* *}$ Values from animals treated with AM251 that are significantly different (multifactorial ANOVA/ LSD; $\mathrm{p}<0.05$ ) than those observed in vehicle- or agonist-treated animals.

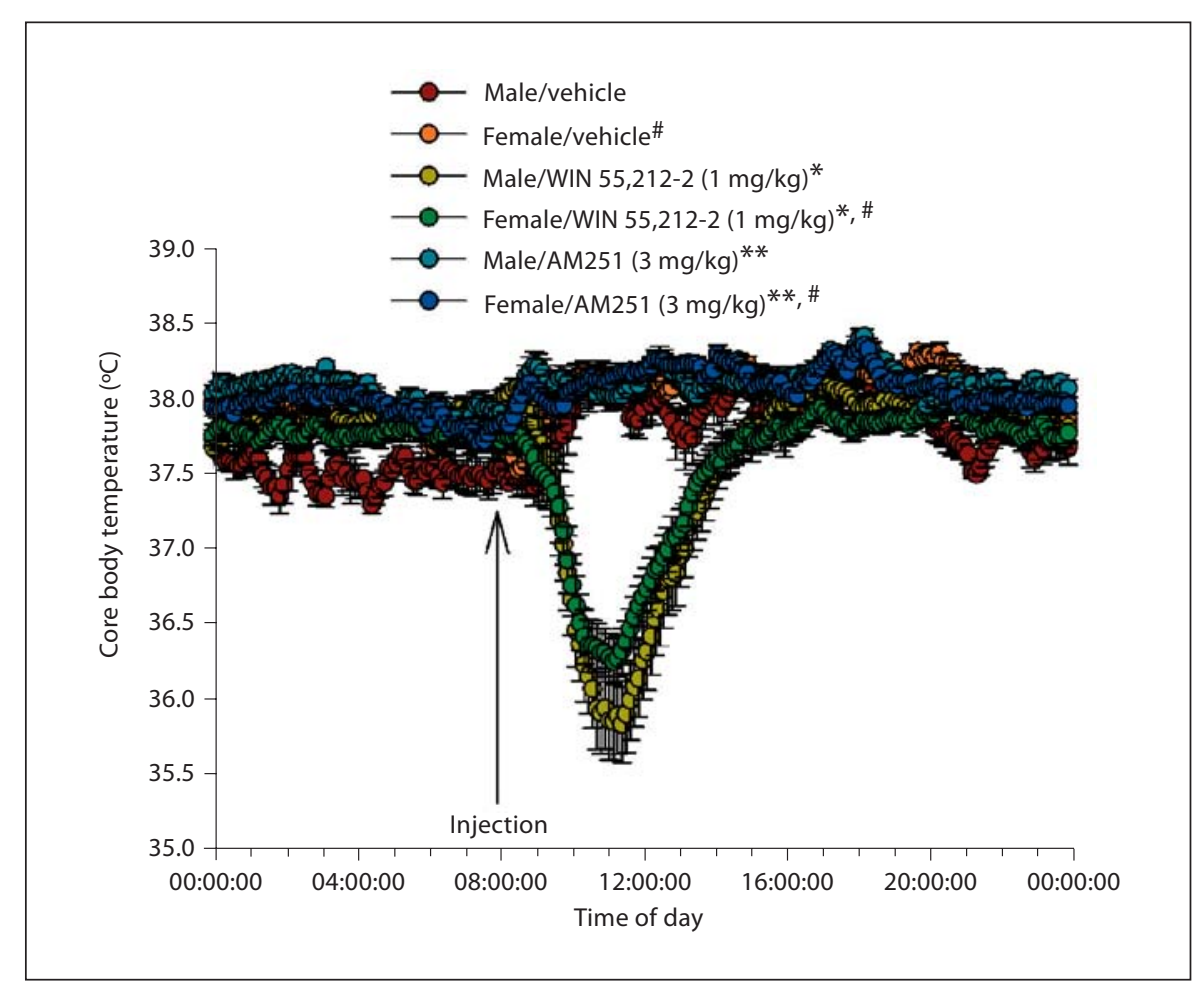

fluorescence with phenotypic markers for POMC neurons, namely $\alpha-\mathrm{MSH}$ and CART (fig. 12; $\mathrm{n}=15$ ).

\section{Decreased Feeding in CB1 Receptor Knockout Mice Is also Sexually Differentiated}

To further characterize the sexually differentiated role of $\mathrm{CB} 1$ receptors in regulating energy homeostasis, we evaluated food intake in $\mathrm{CB} 1$ receptor knockout mice and their littermate wild-type controls. Figure 13 depicts the hourly and daily food intake, as well as the average daily body weight observed over the course of the monitoring period, in gonadally intact male and female animals. The temporal profile for the hourly intake displayed a striking resemblance to that encountered with the CB1 receptor antagonist AM251 in gonadectomized guinea pigs. Multifactorial ANOVA revealed a significant main effect of genotype $\left(\mathrm{F}_{(1,1)}=7.47, \mathrm{p}<0.007\right)$ as well as a significant interaction $\left(\mathrm{F}_{(1,1)}=5.55 ; \mathrm{p}<0.02\right)$, in which male but not female $\mathrm{CB} 1$ receptor knockout mice exhibited a reduced hourly intake relative to their respective wild-type counterparts that was particularly evident during the nocturnal period. This translated into a $\sim 25 \%$ reduction in total intake observed over a 24-hour period and a significantly lower average daily body weight in males, but not females. Taken together, these data demonstrate marked sex differences in the cannabinoid modulation of feeding behavior and body temperature, the former of which correlates with sexual disparities in the sensitivity to cannabinoid-induced presynaptic inhibition of GABAergic neurotransmission at POMC synapses.

\section{Discussion}

The results of the present study demonstrate that cannabinoids regulate appetite in a sexually differentiated manner that involves in part inequities in the CB1 receptor-mediated presynaptic inhibition of ionotropic GABAergic synaptic input onto POMC neurons. These conclusions are based on the following observations: (1) male guinea pigs are much more sensitive to the hyperphagic effect evoked by CB1 receptor activation following systemic administration of WIN 55,212-2 as determined by greater increases in food intake, the amount of food consumed per gram body weight, meal size and meal duration, (2) male guinea pigs and mice also are more responsive to hypophagia due to either $\mathrm{CB} 1$ receptor antagonism by AM251 or genetic knockout as ascertained by more extensive diminutions in hourly intake, the amount of food eaten per gram body weight and meal frequency, 


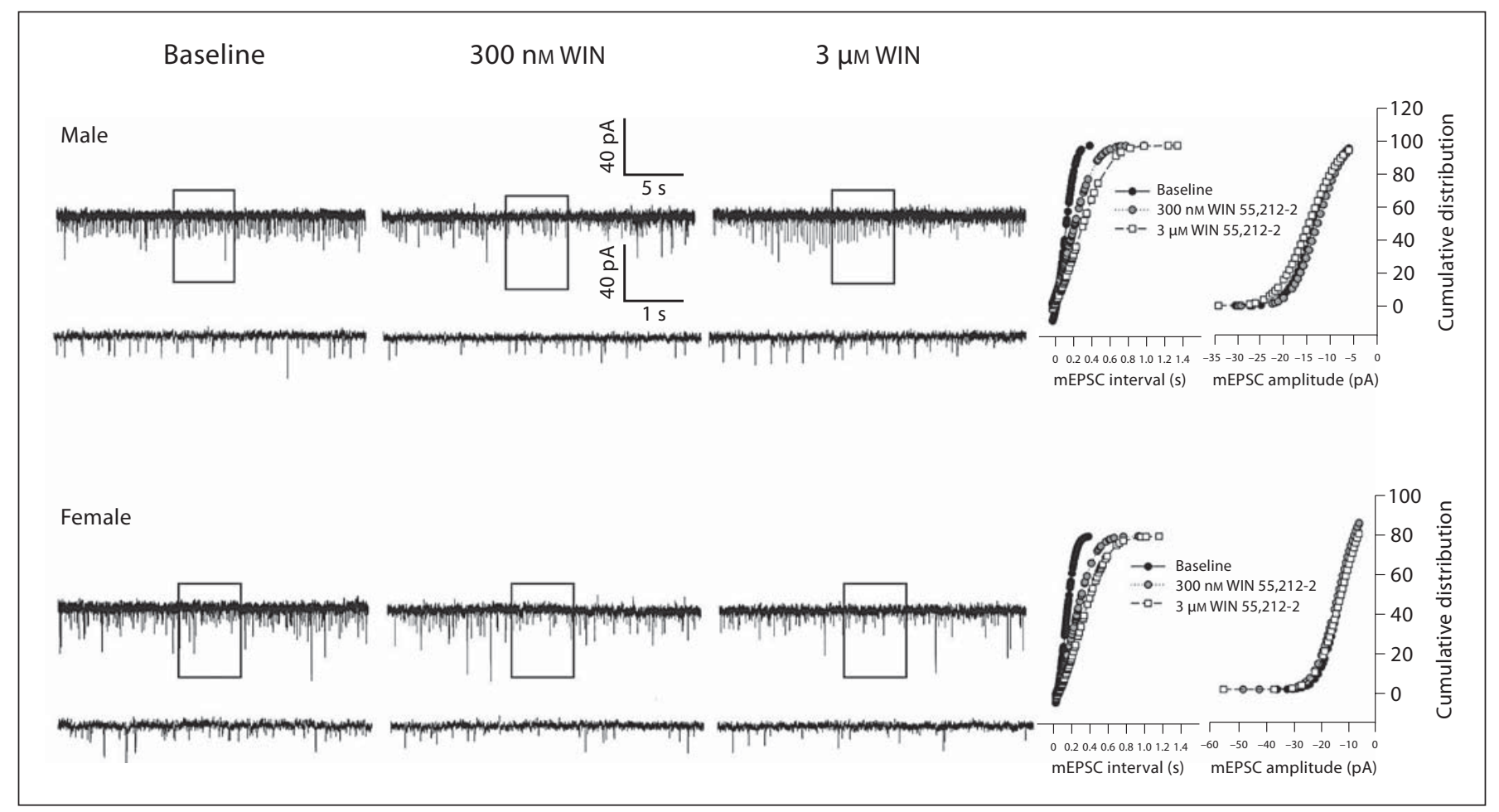

Fig. 9. $\mathrm{CB} 1$ receptor activation decreases $\mathrm{mEPSC}$ frequency to a comparable degree in ARC neurons from male and female animals. There are 6 membrane current traces -3 that are $25 \mathrm{~s}$ in duration and 3 that are $5 \mathrm{~s}$ in duration and represent expanded portions of their respective upper traces that are enclosed by the rectangle that show the mEPSCs in an ARC neuron from a gonadectomized male (top two rows) and female (bottom two rows) under basal (left column), and agonist-stimulated (middle and right columns) conditions. To the right of the traces are cumulative probability plots depicting the interval between contiguous
mEPSCs and their amplitudes for each of the 3 treatment conditions. The ARC neuron from the male animal exhibited a basal mEPSC frequency of $7.4 \mathrm{~Hz}$, whereas the cell from the female animals had a baseline frequency of $9.3 \mathrm{~Hz} .300 \mathrm{nM}$ and $3 \mu \mathrm{M}$ WIN $55,212-2$ elicited a $\sim 33 \%$ and $52 \%$ reduction, respectively, in mEPSC frequency relative to baseline control in the ARC neuron from the male animal, whereas these same concentrations of agonist evoked $\sim 45 \%$ and $60 \%$ decreases in the cell from the female animal. weight gain, as well as a more robust hyperthermia, and (3) WIN 55,212-2 reduces mIPSC frequency in ARC neurons from female guinea pigs, including those immunopositive for $\alpha-\mathrm{MSH}$ and CART, with a considerably greater potency than in cells from their male counterparts. The fact that we also observed frank sexual disparities in the cannabinoid modulation of core body temperature is suggestive of an impressive capacity to influence a broader, more global array of sex differences in the hypothalamic control of homeostasis. Indeed, the cannabinoid regulation of preproCRH and POMC gene expression in the PVN and ARC, respectively, is sexually differentiated [39]. In addition, it is in accordance with broad-based inequities in the cannabinoid-induced antinociception [1,2], locomotor effects [1-3], hemodynamic effects [4, 7], impairment of visuospatial memory [5], subjective ratings of intoxication [7] and interactions with other drugs of abuse $[7,40]$ that have been reported between males and females.

The hyperphagia evoked upon $\mathrm{CB} 1$ receptor activation in the present study is consistent with that observed in humans and other rodent animal models of feeding $[8$, 9], and with what we reported previously for the gonadally intact, fasted male guinea pig [24]. Our data are also in line with a reported sex difference in the cannabinoidinduced consumption of sweetened condensed milk, in which male rats exhibited $\sim 10 \times$ greater sensitivity to the CB1 receptor agonist CP 55,940 administered into the fourth ventricle [6]. The comprehensive analysis of meal pattern performed in the present study extends this finding by providing a much greater resolution of the appetite-modulating properties of cannabinoids. Indeed, the 


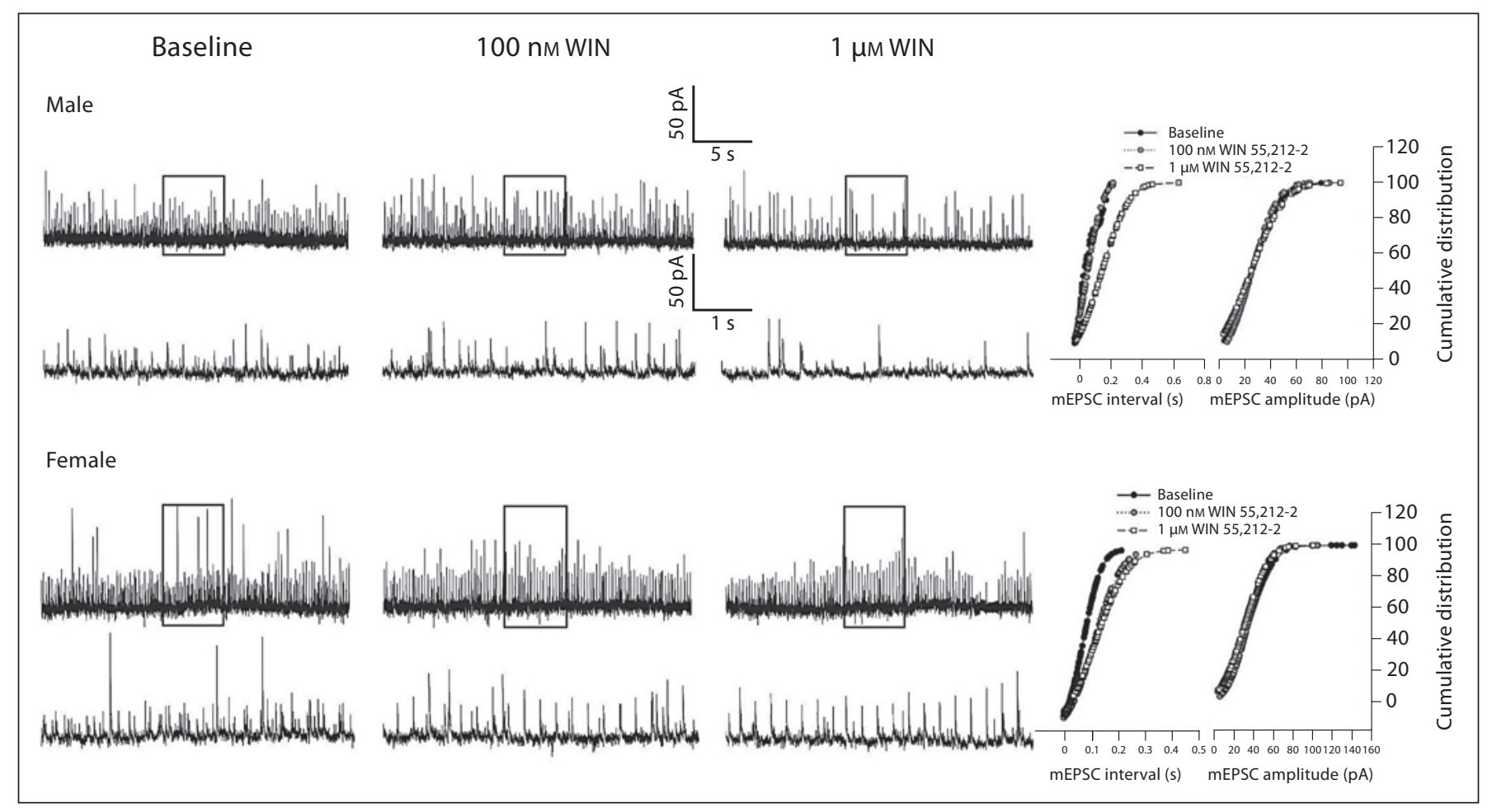

Fig. 10. $C B 1$ receptor activation decreases mIPSC frequency to different degrees in ARC neurons from male and female animals. There are 6 membrane current traces -3 that are $25 \mathrm{~s}$ in duration and 3 that are $5 \mathrm{~s}$ in duration and represent expanded portions of their respective upper traces that are enclosed by the rectangle that show the mIPSCs in an ARC neuron from a gonadectomized male (top two rows) and female (bottom two rows) under basal (left column), and agonist-stimulated (middle and right columns) conditions. To the right of the traces are cumulative probability plots depicting the interval between contiguous mIPSCs and their

24-hour profiles clearly illustrate the sexually differentiated, cannabinoid-induced microstructural changes that occur over time. They provide critical information regarding the period of maximum drug effect after administration $(2-3 \mathrm{~h})$, as well as insight into the appetitive/consummatory aspects of feeding affected by cannabinoid treatment. In females, both the acute and secondary cannabinoid-induced hyperphagia are frequency-dependent and thus due to an enhancement of the appetitive components of eating in the sense that an increase in frequency represents a greater inclination to eat, whereas for males the acute phase is due to an augmentation of the consummatory components of feeding manifested by increases in meal size and duration, and the secondary phase is, as with females, frequency-dependent. On the other hand, the hypophagia caused by antagonism of CB1 amplitudes for each of the 3 treatment conditions. The ARC neuron from the male animal exhibited a basal mIPSC frequency of $12.2 \mathrm{~Hz}$, whereas the cell from the female animal had a baseline frequency of $13.7 \mathrm{~Hz} .100 \mathrm{nM}$ WIN 55,212-2 had no effect on mIPSC frequency relative to baseline control in the ARC neuron from the male animal, whereas the agonist evoked a $\sim 33 \%$ decrease in the cell from the female animal. The higher $1 \mu \mathrm{M}$ concentration elicited a $\sim 54 \%$ reduction in IPSC frequency in the ARC neuron from the male animal, and a $\sim 41 \%$ diminution in the cell from the female animal. receptors in males is associated with a decrease in meal frequency, and thus may reflect a decrease in the appetitive component of feeding. This effect may also be due to an AM251-induced inverse agonism of the CB1 receptor, as has been reported elsewhere [41]. We have shown previously that AM251 increases mEPSC frequency at guinea pig POMC synapses [23, 24]. However, AM251 also modulates dopamine release in the nucleus accumbens in rats [42], which is suggestive of an anhedonic effect that may account, in part, for its anorectic properties [42, 43]. Overall, the anorectic effects that we encountered upon CB1 receptor blockade or ablation were of lesser magnitude than the robust hyperphagic effects observed following CB1 receptor activation. This discrepancy may be attributed to the fact that regular guinea pig chow was used in lieu of a more palatable diet. Indeed, THC is far 

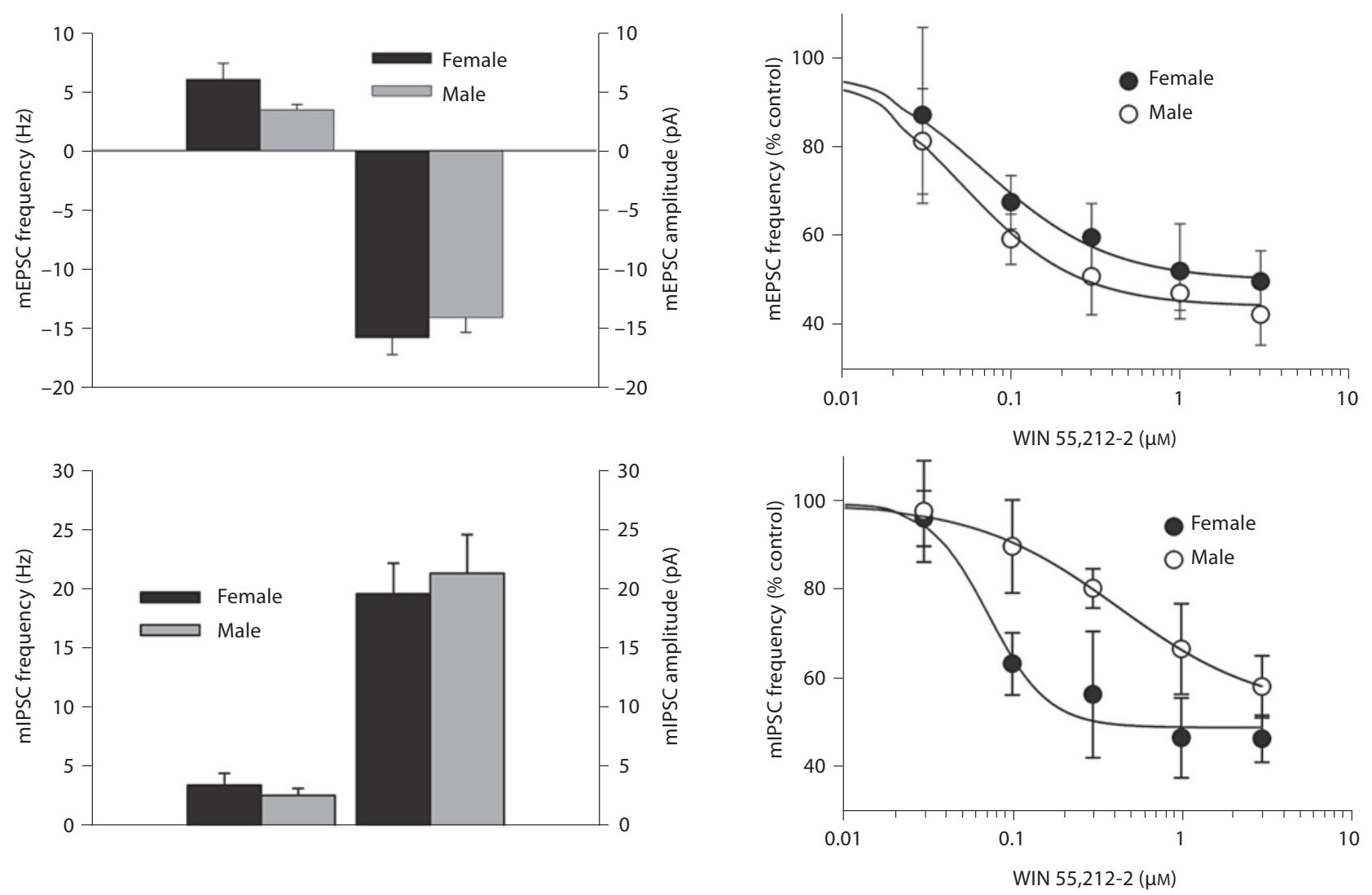

Fig. 11. Sex differences in the CB1 receptor-mediated inhibition of mEPSC and mIPSC frequency. Top left: Composite bar graph illustrating the basal mEPSC frequency and amplitude in ARC neurons from gonadectomized male and female animals. Bars represent means and vertical lines 1 SEM of the basal mEPSC frequency (left) and amplitude (right) measured in ARC neurons obtained from female (black columns; $\mathrm{n}=28$ ) and male (gray columns; $\mathrm{n}=17$ ) animals. Note the nearly twofold higher basal $\mathrm{mEPSC}$ frequency in ARC neurons from females. Top right: Composite dose-response curves for the decrease in mEPSC frequency produced by WIN 55,212-2 in ARC neurons from gonadectomized, female $(\bullet)$ and male $(\bigcirc)$ animals. The curves were fit via logistic equation to the data points. Symbols represent means and vertical lines 2 SEM $(n=2-12)$ of the mEPSC frequency seen with varying concentrations of WIN 55,212-2 that were normalized to

more effective in stimulating appetite in rats fed a highfat diet compared to those fed normal chow [44], and AM251 dramatically decreased food intake, body weight and adipose tissue mass in obese mice fed a high-fat Western diet [45]. Future studies will ascertain whether sex differences in the cannabinoid modulation of appetite transcend the exposure to different diets. their respective control values. Bottom left: Composite bar graph illustrating the basal mIPSC frequency and amplitude in ARC neurons from gonadectomized male and female animals. Bars represent means and vertical lines 1 SEM of the basal MIPSC frequency (left) and amplitude (right) measured in ARC neurons obtained from female (black columns; $\mathrm{n}=11$ ) and male (gray columns; $\mathrm{n}=9$ ) animals. Bottom right: Composite dose-response curves for the decrease in mIPSC frequency produced by WIN 55,212-2 in ARC neurons from gonadectomized, female (-) and male $(\bigcirc)$ animals. The curves were fit via logistic equation to the data points. Symbols represent means and vertical lines 2 SEM $(\mathrm{n}=2-12)$ of the mIPSC frequency seen with varying concentrations of WIN 55,212-2 that were normalized to their respective control values. Note the prominent rightward shift in the agonist dose-response curve for the male.
We have demonstrated previously that cannabinoids presynaptically inhibit glutamate and GABA release from terminals impinging upon POMC neurons in both male [24] and female [23] guinea pigs. Presently we show that females exhibit a higher degree of tonic glutamatergic synaptic input onto POMC neurons than do males, and that WIN 55,212-2 presynaptically inhibits glutamate re- 

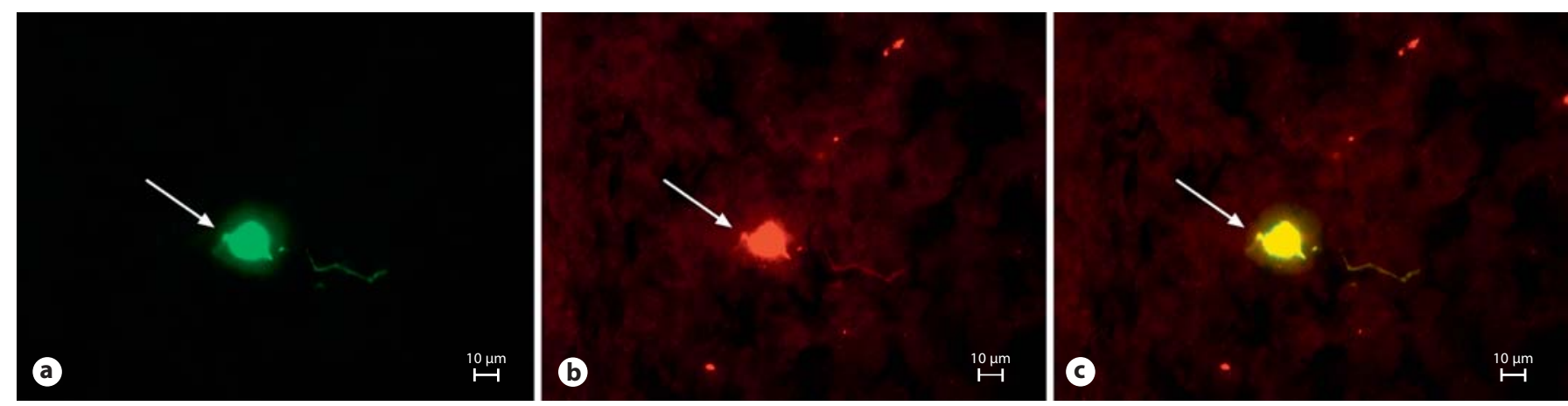

Fig. 12. Double-labeling of a cell that is immunopositive for phenotypic markers characteristic of ARC POMC neurons. a Color photomicrograph of the biocytin-streptavidin-AF488 labeling seen in an ARC neuron (denoted by the arrow). $\mathbf{b}$ Color photomicrograph of the $\alpha-\mathrm{MSH}$ immunofluorescence in the perikarya in (a) as visualized with AF546 (also denoted by the arrow). c Composite overlay illustrating the double labeling in this ARC neuron. Calibration bar $=10 \mu \mathrm{m}$ for all photomicrographs.

lease with equivalent potency and efficacy in females and males. This increased basal level of glutamatergic neurotransmission in females is consistent with sex differences in $\mathrm{N}$-methyl-D-aspartate receptor-mediated regulation of $\mathrm{A}_{12}$ dopamine neurons [46], and may reflect either an increased number of asymmetric synapses impinging on POMC neurons as has been described for sex differences in the synaptic organization of the medial amygdala [47], or a comparatively larger number of vesicular glutamate versus GABA transporters like those expressed in dual-phenotype amino acid neurotransmitter-containing nerve terminals impinging on GnRH neurons [48]. On the other hand, the agonist presynaptically inhibits GABAergic neurotransmission at POMC synapses with an approximately sixfold greater potency in females than in males. Thus, while CB1 receptor activation decreases glutamate release to a similar extent in females and males, ultimately there would be higher levels of glutamate at POMC synapses due to the elevated basal release of the transmitter in females. Conversely, males are comparatively refractory to the $\mathrm{CB} 1$ receptor-mediated presynaptic inhibition of GABA release, and in the presence of cannabinoids males would exhibit greater levels of GABA at POMC synapses than females. In essence, cannabinoids are shifting the balance of excitation and inhibition in a sexually differentiated manner. In males, the lower basal release of glutamate coupled with a less extensive $\mathrm{CB} 1$ receptor-mediated decrease in GABA release favors $\mathrm{GABA}_{\mathrm{A}}$ receptor-mediated inhibition at POMC synapses, whereas in females the net balance is shifted in favor of glutamatergic excitation. Therefore, females are more likely to exhibit higher impulse traffic along the axons of
POMC neurons, and thus more anorectic peptide release and less appetite stimulation upon CB1 receptor activation than males. The corroborating sex difference in energy homeostasis exhibited by the CB1 receptor knockout mice is very similar to that previously reported for transgenic mice lacking the posttranslational POMC byproduct $\beta$-endorphin, in which male $\beta$-endorphin knockout mice show more persistent hyperphagia and more pronounced obesity with ad libitum access to food, as compared to their female counterparts $[49,50]$. This serves once again to reinforce the notion that POMC neurons are a critical neuroanatomical substrate for the sexually dimorphic cannabinoid regulation of appetite.

The sex differences presently observed in the guinea pig were characterized under conditions devoid of circulating reproductive hormones. This suggests that organizational effects of gonadal steroids are integral to the sexual disparities in the cannabinoid modulation of appetite and metabolism. Indeed, the sexually differentiated cannabinoid modulation of appetite that we observed in gonadally intact male and female mice is very similar to that encountered in gonadectomized male and female guinea pigs. In addition, the establishment of sex differences in primates and guinea pigs including, but not limited to, morphologic differences in the hypothalamus and limbic system, the expression of aromatase and gonadal steroidinduced negative feedback on gonadotropin secretion, is due to in utero and neonatal exposure to androgens [51]. Moreover, in utero androgenization of developing fetal female mice increases the GABAergic synaptic input onto $\mathrm{GnRH}$ neurons observed in adulthood [52]. However, this does not rule out the potential for activational influ- 


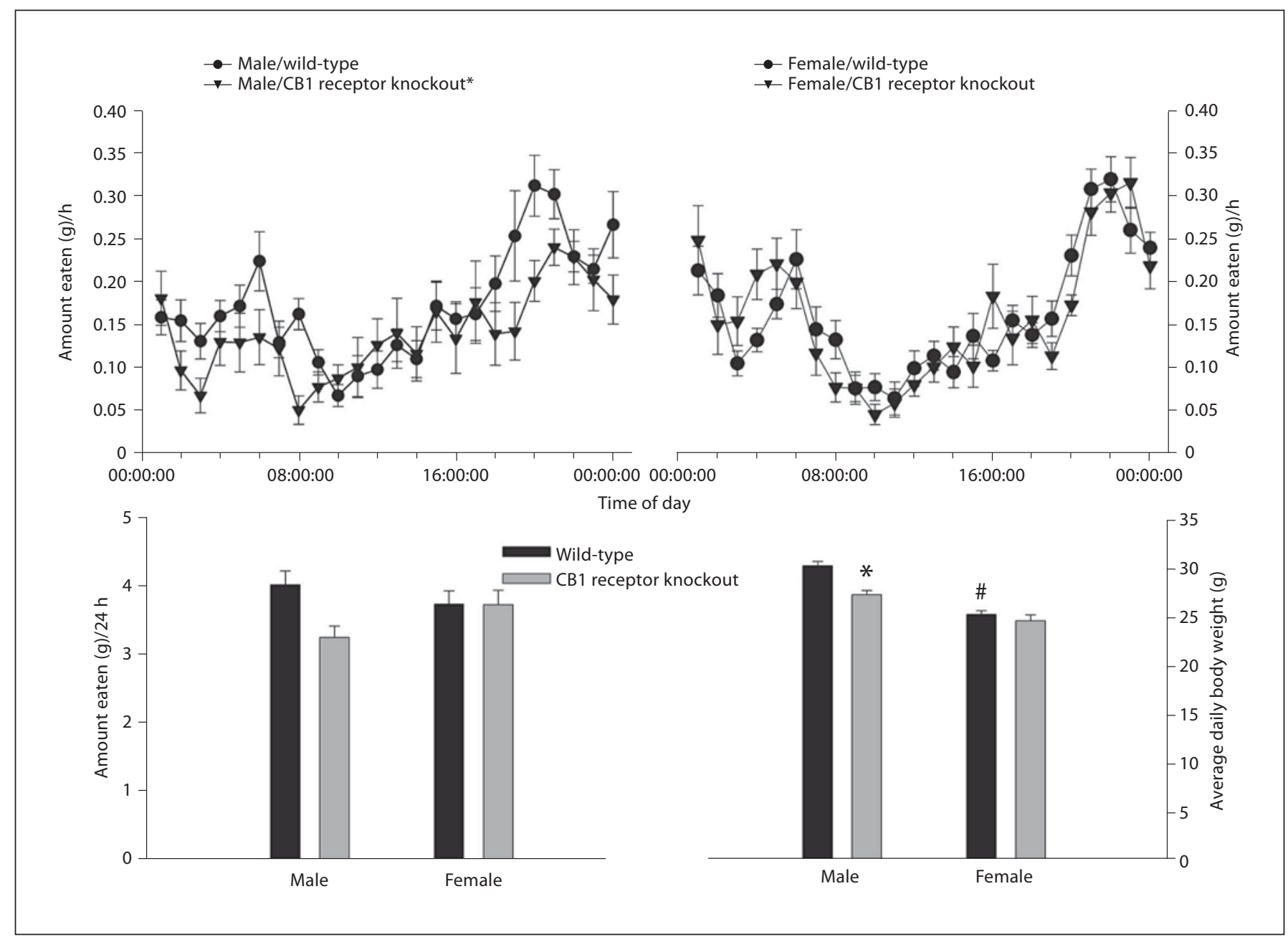

Fig. 13. Sex differences in the cannabinoid regulation of energy homeostasis in gonadally intact, male and female CB1 receptor knockout mice vs. their respective wild-type littermate controls. The top row illustrates the sexually dimorphic alterations in hourly food intake. The symbols represent means and vertical lines 2 SEM $(n=4)$ of the total amount of food consumed every hour over a 24 -hour period. The bottom row shows the changes in daily food intake (left panel) and body weight (right panel). The vertical bars represent means and vertical lines 1 SEM $(n=4)$ of the total amount of food consumed over $24 \mathrm{~h}$ (left panel) and the average daily body weight observed over the entire monitoring period (right panel). ${ }^{*}$ Values from male CB1 receptor knockout mice that are significantly different (multifactorial ANOVA/LSD; $\mathrm{p}<0.05$ ) than those observed in littermate controls. "Values from females that are significantly different (multifactorial ANOVA/ LSD; $\mathrm{p}<0.05)$ than those from their male counterparts. ences of gonadal steroid hormones on the cannabinoid modulation of energy homeostasis. Gonadal steroids are known to alter food intake, and it is compelling to hypothesize that they do so through interactions with cannabinoids on the hypothalamic feeding circuitry. For example, estrogen attenuates and accentuates the cannabinoid-induced presynaptic inhibition of glutamatergic and GABAergic synaptic input, respectively, onto anorexigenic POMC neurons [23], and this is due presumably to its ability to modulate the coupling of metabo- tropic receptors to their effector systems [53]. Estrogen also decreases food intake and weight gain in rats [54] and guinea pigs $[55,56]$, and in humans, energy intake is lower in the estrogen-dominated follicular phase than in the progesterone-dominated luteal phase [57]. On the other hand, testosterone stimulates GABA turnover in the rostral and mediobasal hypothalamus $[58,59]$. In addition, aging-induced anorexia is associated with reductions in testosterone levels and with a decreased capacity for refeeding-induced weight gain following prolonged 
fasting $[60,61]$. Furthermore, testosterone and nandrolone cause weight gain and increase lean body mass to effectively counter AIDS-associated wasting [62, 63]. Future experiments will evaluate whether gonadal steroids differentially influence cannabinoid modulation of feeding via putative activational effects.

In conclusion, the results of the present study demonstrate clear and marked sex differences in the cannabinoid modulation of energy homeostasis. Overall, males are substantially more responsive to the hyperphagic and hypophagic, as well as the hypothermic and hyperthermic, effects of $\mathrm{CB} 1$ receptor agonists and antagonists, respectively. This may be attributed in part to disparities in CB1 receptor-mediated regulation of GABAergic synaptic input onto anorexigenic POMC neurons, in which males exhibit a comparatively blunted presynaptic modulation of GABA release. Our findings are in agreement with recent papers touting the efficacy of THC to stimulate appetite in patients suffering from HIV/AIDS- or cancer-related cachexia [10-12] or from chronic pain [64], in which the vast majority of the study participants were male. By contrast, in another trial describing a lack of effect of THC on cancer-related anorexia-cachexia, the gender composition of the study was considerably more equitable [65]. This indicates that gender should be taken into account when considering the use of cannabinoids to modulate appetite in these various clinical scenarios.

\section{Acknowledgements}

The authors thank Shelley Mach for her technical assistance. This study was supported by PHS Grant DA00521 and an intramural research grant from Western University of Health Sciences.

\section{References}

$\nabla_{1}$ Tseng AH, Craft RM: Sex differences in antinociceptive and motoric effects of cannabinoids. Eur J Pharmacol 2001;430:41-47.

- Tseng AH, Harding JW, Craft RM: Pharmacokinetic factors in sex differences in $\Delta^{9}$-tetrahydrocannabinol-induced behavioral effects in rats. Behav Brain Res 2004;154:7783.

3 Wiley JL: Sex-dependent effects of $\Delta^{9}$-tetrahydrocannabinol on locomotor activity in mice. Neurosci Lett 2003;352:77-80.

4 Mathew RJ, Wilson WH, Davis R: Postural syncope after marijuana: a transcranial Doppler study of the hemodynamics. Pharmacol Biochem Behav 2003;75:309-318.

5 Pope HG, Jacobs A, Mialet JP, YurgelunTodd D, Gruber S: Evidence for a sex-specific residual effect of cannabis on visuospatial memory. Psychother Psychosom 1997;66: 179-184.

6 Miller CC, Murray TF, Freeman KG, Edwards GL: Cannabinoid agonist, CP 55,940, facilitates intake of palatable foods when injected into the hindbrain. Physiol Behav 2004;80:611-616.

7 Penetar DM, Kouri EM, Gross MM, McCarthy EM, Rhee CK, Peters EN, Lukas SE: Transdermal nicotine alters some of marijuana's effects in male and female volunteers. Drug Alcohol Depend 2005;79:211-223.

8 Fride E, Bregman T, Kirkham TC: Endocannabinoids and food intake: newborn suckling and appetite regulation in adulthood. Exp Biol Med 2005;230:225-234.

-9 Matias I, Di Marzo V: Endocannabinoids and the control of energy balance. Trends Endocrinol Metab 2007;18:27-37.
10 Inui A: Cancer anorexia-cachexia syndrome: current issues in research and management. CA Cancer J Clin 2002;52:72-91.

11 Haney M, Rabkin J, Gunderson E, Foltin RW: Dronabinol and marijuana in HIV+ marijuana smokers: acute effects on caloric intake and mood. Psychopharmacology (Berl) 2005;181:170-178.

12 Walsh D, Kirkova J, Davis MP: The efficacy and tolerability of long-term use of dronabinol in cancer-related anorexia: a case series. J Pain Symptom Manage 2005;30:493-495.

13 Pi-Sunyer FX, Aronne LJ, Heshmati HM, Devin J, Rosenstock J: Effect of Rimonabant, a cannabinoid-1 receptor blocker, on weight and cardiometabolic risk factors in overweight or obese patients. JAMA 2006;295: 761-775.

14 Wierzbicki AS: Rimonabant: endocannabinoid inhibition for the metabolic syndrome. Int J Clin Pract 2006;60:1697-1706.

15 Gómez R, Navarro M, Ferrer B, Trigo JM, Bilbao A, del Arco I, Cippitelli A, Nava F, Piomelli D, Rodríguez de Fonseca F: A peripheral mechanism for $\mathrm{CB} 1$ cannabinoid receptor-dependent modulation of feeding. J Neurosci 2002;22:9612-9617.

16 Cota D, Marsicano G, Tschöp M, Grübler Y, Flachskamm C, Schubert M, Auer D, Yassouridis A, Thöne-Reineke C, Ortmann S, Tomassoni F, Cervino C, Nisoli E, Linthhorst ACE, Pasquali R, Lutz B, Stalla GK, Pagotto U: The endogenous cannabinoid system affects energy balance via central orexigenic drive and peripheral lipogenesis. J Clin Invest 2003;112:423-431.
Cota D, Marsicano G, Lutz B, Vicennati V, Stalla GK, Pasquali R, Pagotto U: Endogenous cannabinoid system as a modulator of food intake. Int J Obesity 2003;27:289-301.

18 Jamshidi N, Taylor DA: Anandamide administration into the ventromedial hypothalamus stimulates appetite in rats. $\mathrm{Br} \mathrm{J}$ Pharmacol 2001;134:1151-1154.

19 Jo YH, Chen YJL, Chua SC, Talmage DA, Role LW: Integration of endocannabinoid and leptin signaling in an appetite-related neural circuit. Neuron 2005;48:1055-1066.

20 Huang H, Acuna-Goycolea C, Li Y, Cheng HM, Obrietan K, van den Pol AN: Cannabinoids excite hypothalamic melanin-concentrating hormone but inhibit hypocretin/ orexin neurons: implications for cannabinoid actions on food intake and cognitive arousal. J Neurosci 2007;27:4870-4881.

- 21 Gamber KM, Macarthur H, Westfall TC: Cannabinoids augment the release of neuropeptide $\mathrm{Y}$ in the rat hypothalamus. Neuropharmacology 2005;49:646-652.

22 Hentges ST, Low MJ, Williams JT: Differential regulation of synaptic inputs by constitutively released endocannabinoids and exogenous cannabinoids. J Neurosci 2005;25: 9746-9751.

23 Nguyen QH, Wagner EJ: Estrogen differentially modulates the cannabinoid-induced presynaptic inhibition of amino acid neurotransmission in proopiomelanocortin neurons of the arcuate nucleus. Neuroendocrinology 2006;84:123-137.

24 Ho J, Cox JM, Wagner EJ: Cannabinoid-induced hyperphagia: Correlation with inhibition of proopiomelanocortin neurons? Physiol Behav 2007;92:507-519. 
-25 Di Marzo V, Goparahu SK, Wang L, Liu J, Bátkai S, Járai Z, Fezza F, Miura GI, Palmiter $\mathrm{RD}$, Sugiura T, Kunos G: Leptin-regulated endocannabinoids are involved in maintaining food intake. Nature 2001;410:822-825.

-26 Malcher-Lopes R, Di S, Marcheselli VS, Weng FJ, Stuart CT, Bazan NG, Tasker JG: Opposing crosstalk between leptin and glucocorticoids rapidly modulates synaptic excitation via endocannabinoid release. J Neurosci 2006;26:6643-6650.

27 Horton BJ, West CE, Turley SD: Diurnal variation in the feeding pattern of guinea pigs. Nutr Metabol 1975;18:294-301.

28 Hirsch E, Collier G: The ecological determinants of reinforcement in the guinea pig. Physiol Behav 1974;12:239-249.

-29 Sohlström A, Katsman A, Kind KL, Grant PA, Owens PC, Robinson JS, Owens JA: Effects of acute and chronic food restriction on the insulin-like growth factor axis in the guinea pig. J Endocrinol 1998;157:107-114.

30 Mennini T, Bizzi A, Caccia S, Codegoni A, Fracasso C, Frittoli E, Guiso G, Padura IM, Taddei C, Uslenghi A, Garattini S: Comparative studies on the anorectic activity of $d$ fenfluramine in mice, rats and guinea pigs. Naunyn-Schmiedeberg's Arch Pharmacol 1991;343:483-490.

- 31 Anelli M, Bizzi A, Caccia S, Codegoni AM, Fracasso C, Garattini S: Anorectic activity of fluoxetine and norfluoxetine in mice, rats and guinea-pigs. J Pharm Pharmacol 1992; 44:696-698.

- 32 Odumosu A: Vitamin C and weight reducing drugs on brain ascorbic acid in guinea pigs. Acta Vitaminol Enzymol 1981;3:96-102.

-33 Knobil E: On the control of gonadotropin secretion in the rhesus monkey. Recent Prog Horm Res 1974;30:1-36.

-34 Owen JA: Physiology of the menstrual cycle. Am J Clin Nutr 1975;28:333-338.

- 35 Terasawa E, Wiegand SJ: Effects of hypothalamic deafferentation on ovulation and estrous cyclicity in the female guinea pig. Neuroendocrinology 1978;26:229-248.

- 36 Garris DR, Foreman D: Follicular growth and atresia during the last half of the luteal phase of the guinea pig estrous cycle: relation to serum progesterone and estradiol levels and utero-ovarian blood flow. Endocrinology 1984;115:73-77.

- 37 Wagner EJ, Rønnekleiv OK, Bosch MA, Kelly MJ: Estrogen biphasically modifies hypothalamic GABAergic neuronal function concomitantly with negative and positive control of luteinizing hormone release. J Neurosci 2001;21:2085-2093.

- 38 Ronnekleiv OK, Loose MD, Erickson KR, Kelly MJ: A method for immunocytochemical identification of biocytin-labeled neurons following intracellular recording. BioTechniques 1990;9:432-438.
39 Corchero J, Manzanares J, Fuentes JA: Role of gonadal steroids in the corticotropin-releasing hormone and proopiomelanocortin gene expression response to $\Delta^{9}$-tetrahydrocannabinol in the hypothalamus of the rat. Neuroendocrinology 2001;74:185-192.

40 Viveros MP, Marco EM, File SE: Nicotine and cannabinoids: Parallels, contrasts and interactions. Neurosci Biobehav Rev 2006; 30:1161-1181.

41 Hodge J, Bow JP, Plyler KS, Vemuri K, Wisniecki A, Salamone JD, Makriyannis A, McLaughlin PJ: The cannabinoid CB1 receptor inverse agonist AM 251 and antagonist AM 4113 produce similar effects on the behavioral satiety sequence in rats. Behav Brain Res 2008;193:298-305.

42 Sinnayah P, Jobst EE, Rathner JA, CalderaSiu AD, Tonelli-Lemos L, Eusterbrock AJ, Enriori PJ, Pothos EN, Grove KL, Cowley MA: Feeding induced by cannabinoids is mediated independently of the melanocortin system. PLoS ONE 2008;3:e2202.

43 Cota D, Tschöp MH, Horvath TL, Levine AS: Cannabinoids, opioids and eating behavior: the molecular face of hedonism? Brain Res Rev 2006;51:85-107.

44 Koch JE: $\Delta^{9}$-THC stimulates food intake in Lewis rats: effects on chow, high-fat and sweet high-fat diets. Pharmacol Biochem Behav 2001;68:539-543.

45 Hildebrandt AL, Kelly-Sullivan DM, Black SC: Antiobesity effects of chronic CB1 receptor antagonist treatment in diet-induced obese mice. Eur J Pharmacol 2003;462:125132.

46 Wagner EJ, Moore KE, Lookingland KJ: Sexual differences in N-methyl-D-aspartate receptor-mediated regulation of tuberoinfundibular dopaminergic neurons in the rat. Brain Res 1993;611:139-146.

47 Cooke BM, Woolley CS: Sexually dimorphic synaptic organization of the medial amygdala. J Neurosci 2006;25:10759-10767.

48 Ottem EN, Godwin JG, Krishnan S, Petersen SL: Dual phenotype GABA/glutamate neurons in $\beta$ adult preoptic area: sexual dimorphism and function. J Neurosci 2004;24: 8097-8105.

49 Appleyard SM, Hayward M, Young JI, Butler AA, Cone RD, Rubinstein M, Low MJ: A role for endogenous $\beta$-endorphin in energy homeostasis. Endocrinology 2003; 144:17531760.

-50 Low MJ, Hayward MD, Appleyard SM, Rubinstein M: State-dependent modulation of feeding behavior by proopiomelanocortinderived $\beta$-endorphin. Ann NY Acad Sci 2003;994:192-201.

51 Resko JA, Roselli CE: Prenatal hormones organize sex differences of the neuroendocrine reproductive system: observations on guinea pigs and nonhuman primates. Cell Mol Neurobiol 1997;17:627-648.

-52 Sullivan SD, Moenter SM: Prenatal androgens alter GABAergic drive to gonadotropin-releasing hormone neurons: implica- tions for a common fertility disorder. Proc Natl Acad Sci 2005;101:7129-7134.

53 Kelly MJ, Rønnekleiv OK, Ibrahim N, Lagrange $\mathrm{AH}$, Wagner EJ: Estrogen modulation of $\mathrm{K}^{+}$channel activity in hypothalamic neurons involved in the control of the reproductive axis. Steroids 2002;67:447-456.

54 Geary N: Estradiol, CCK and satiation. Peptides 2001;22:1251-1263.

55 McCaffrey TA, Czaja JA: Diverse effects of estradiol-17ß: concurrent suppression of appetite, blood pressure and vascular reactivity in conscious, unrestrained animals. Physiol Behav 1989;45:649-657.

56 Qiu J, Bosch MA, Tobias SC, Krust A, Graham SM, Murphy SJ, Korach KS, Chambon P, Scanlan TS, Rønnekleiv OK, Kelly MJ: A g-protein-coupled estrogen receptor is involved in hypothalamic control of energy homeostasis. J Neurosci 2006;26:56495655.

57 Johnson WG, Corrigan SA, Lemmon CR, Bergeron KB, Crusco AH: Energy regulation over the menstrual cycle. Physiol Behav 1994;56:523-527.

58 Grattan DR, Selmanoff M: Castration-induced decrease in the activity of medial preoptic and tuberoinfundibular GABAergic neurons is prevented by testosterone. Neuroendocrinology 1994;60:141-149.

59 Grattan DR, Selmanoff M: Prolactin- and testosterone-induced inhibition of LH secretion after orchidectomy: role of preoptic and tuberoinfundibular $\gamma$-aminobutyric acidergic neurones. J Endocrinol 1994;143:165174.

60 Chapman IM: Endocrinology of anorexia of ageing. Best Pract Res Clin Endocrinol Metab 2004; 18:437-452.

61 Wolden-Hanson T: Mechanisms of the anorexia of aging in the Brown Norway rat. Physiol Behav 2006;88:267-276.

62 Corcoran C, Grinspoon S: Treatments for wasting in patients with the acquired immunodeficiency syndrome. N Engl J Med 1999; 340:1740-1750.

63 Batterham MJ, Garsia R: A comparison of megestrol acetate, nandrolone decanoate and dietary counselling for HIV associated weight loss. Int J Androl 2001;24:232-240.

64 Lynch ME, Young J, Clark AJ: A case series of patients using medical marihuana for management of chronic pain under the $\mathrm{Ca}$ nadian Marihuana Medical Access Regulations. J Pain Symptom Manage 2006;32:497501.

65 Strasser F, Luftner D, Possinger K, Ernst G, Ruhstaller T, Meissner W, Ko YD, Schnelle M, Reif M, Cerny T: Comparison of orally administered cannabis extract and delta-9tetrahydrocannabinol in treating patients with cancer-related anorexia-cachexia syndrome: a multicenter, phase III, randomized, double-blind, placebo-controlled clinical trial from the cannabis-study-group. J Clin Oncol 2006;24:3394-3400. 